\title{
Dietary Polyphenols as Modulators of Brain Functions: Biological Actions and Molecular Mechanisms Underpinning Their Beneficial Effects
}

\author{
David Vauzour \\ Department of Nutrition, Norwich Medical School, University of East Anglia, Norwich NR4 7TJ, UK \\ Correspondence should be addressed to David Vauzour, d.vauzour@uea.ac.uk
}

Received 19 February 2012; Accepted 30 March 2012

Academic Editor: Tullia Maraldi

Copyright ( 2012 David Vauzour. This is an open access article distributed under the Creative Commons Attribution License, which permits unrestricted use, distribution, and reproduction in any medium, provided the original work is properly cited.

\begin{abstract}
Accumulating evidence suggests that diet and lifestyle can play an important role in delaying the onset or halting the progression of age-related health disorders and to improve cognitive function. In particular, polyphenols have been reported to exert their neuroprotective actions through the potential to protect neurons against injury induced by neurotoxins, an ability to suppress neuroinflammation, and the potential to promote memory, learning, and cognitive function. Despite significant advances in our understanding of the biology of polyphenols, they are still mistakenly regarded as simply acting as antioxidants. However, recent evidence suggests that their beneficial effects involve decreases in oxidative/inflammatory stress signaling, increases in protective signaling and neurohormetic effects leading to the expression of genes that encode antioxidant enzymes, phase- 2 enzymes, neurotrophic factors, and cytoprotective proteins. Specific examples of such pathways include the sirtuin-FoxO pathway, the NF- $\kappa \mathrm{B}$ pathway, and the Nrf-2/ARE pathway. Together, these processes act to maintain brain homeostasis and play important roles in neuronal stress adaptation and thus polyphenols have the potential to prevent the progression of neurodegenerative pathologies.
\end{abstract}

\section{Introduction}

A gradual increase in human life span, with people over the age of 60, is expected to double between 2000 and 2050 [1]. As the elderly population expands, the prevalence of both Alzheimer's disease (AD) and Parkinson's disease (PD) is likely to augment, therefore having profound economical and social implications. Although the exact cause is not yet finally known, it has been postulated that the behavioural and neuronal declines associated with these age-related neurodegenerative disorders are triggered by multifactorial events including neuroinflammation, glutamatergic excitotoxicity, increases in iron, and/or depletion of endogenous antioxidants [2-4]. Therefore, it becomes imperative to develop drugs that possibly exert neuroprotective actions in order to prevent or even reverse age-related health disorders. One such possibility is the use of nutritional substances such as polyphenols $[5,6]$. For example, a large number of dietary interventions using polyphenol rich foods or beverages, in particular those using tea [7-9], Gingko Biloba $[10,11]$, cocoa $[12,13]$ and blueberry [14-16], have demonstrated beneficial effects on memory and learning in both animals and humans. Furthermore, individual flavonoids such as the citrus flavanone tangeretin, have been observed to maintain nigrostriatal integrity and functionality following lesioning with 6-hydroxydopamine, suggesting that it may serve as a potential neuroprotective agent against the underlying pathology associated with PD [17]. While historically research focused on their antioxidant properties [18], recent data support the view that polyphenols, and their in vivo metabolites, do not act as conventional hydrogen-donating antioxidants but may exert modulatory actions in cells through actions at protein kinase and lipid kinase signalling pathways [19] and may even involve hormetic effects to protect neurons against the oxidative and inflammatory stressors [20]. This paper will describe the potential of polyphenols to modulate neuroinflammation, to counteract neurotoxins induced neurodegenerative disorders, and to enhance memory, learning, and cognitive performances. Neuroprotective mechanisms through the ability of polyphenols to interact 
with neuronal signaling pathways and to mediate endogenous cellular defense systems including sirtuin, NF- $\kappa \mathrm{B}, \mathrm{Nrfs}$, and related pathways will be also presented.

\section{Sources and Structures of Polyphenols}

Polyphenols are a group of naturally occurring phytochemicals which are present in high amounts in fruits, vegetables, and natural products and are characterised by the presence of multiple hydroxyl groups on aromatic rings. These compounds are divided into two main categories: the flavonoids and nonflavonoids, based on the number of phenol rings and the way in which these rings interact.

2.1. Flavonoids. Flavonoids are polyphenolic compounds comprising 15 carbons, with two aromatic rings connected by a three-carbon bridge $\left(\mathrm{C}_{6}-\mathrm{C}_{3}-\mathrm{C}_{6}\right)$. Hydroxylation in position 3 of C-ring allows the differentiation of flavanonols from flavanones since they share a similar structure based on the 2,3-dihydro-2-phenylchromen-4-one skeleton. From these central intermediates, the pathway diverges into several side branches, each resulting in a different class of flavonoids. Flavonoids share a common feature which consists of two aromatic carbon rings, benzopyran (A and $\mathrm{C}$ rings) and benzene ( $\mathrm{B}$ ring) and may be divided in various subgroups based on the degree of the oxidation of the C-ring, the hydroxylation pattern of the ring structure, and the substitution of the 3-position. The main dietary groups of flavonoids are (1) flavones (e.g., apigenin, luteolin), which are found in parsley and celery. Hydroxylation on position 3 of the flavone structure gives rise to the 3-hydroxyflavones also known as the (2) flavonols (e.g., kaempferol, quercetin), which are found in onions, leeks, and broccoli; (3) isoflavones (e.g., daidzein, genistein), which are mainly found in soy and soy products. These compounds have a large structural variability, and more than 600 isoflavones have been identified to date and are classified according to oxidation level of the central pyran ring; (4) flavanones/flavanonols (e.g., hesperetin, naringenin/astilbin, engeletin), which are mainly found in citrus fruit, herbs (oregano), and wine; (5) flavanols (e.g., (+)catechin, (-)-epicatechin, epigallocatechin, and epigallocatechin gallate (EGCG), which are abundant in green tea, red wine, and chocolate. Flavanols are found both as monomers and oligomers referred to as condensed tannins or proanthocyanidins. Variations in their structures lie in the hydroxylation pattern of the $\mathrm{B}$ ring and the presence of gallic acid in position 3. The lack of a double bond at the 2-3 position and the presence of a 3-hydroxyl group on the $\mathrm{C}$ ring create two centres of asymmetry; (6) anthocyanidins (e.g., pelargonidin, cyanidin, and malvidin), whose sources include red wine and berry fruits. These compounds exist as glycosides in plants, are water-soluble, and appear red or blue according to $\mathrm{pH}$. Individual anthocyanins arise from the variation in number and arrangement of the hydroxyl and methoxy groups around the 3 rings (Figure 1).

2.2. Nonflavonoids. The nonflavonoid group may be separated into two different classes: (1) the phenolic acids, including the hydroxybenzoic acids (HBAs; $\mathrm{C}_{1}-\mathrm{C}_{3}$ skeleton) and hydroxycinnamic acids (HCAs; $\mathrm{C}_{3}-\mathrm{C}_{6}$ skeleton) and (2) the stilbenes $\left(\mathrm{C}_{6}-\mathrm{C}_{2}-\mathrm{C}_{6}\right.$ skeleton).

The most common phenolic acids are not present in plants in a free state but occur as simple esters of glucose, tartaric acid, and quinic acid [21], and variations in the structure mainly lie in the hydroxylation and methoxylation pattern of the aromatic cycle [22]. HBAs are derivatives of the hydroxybenzoic acids such as $p$-hydroxybenzoic, protocatechuic, and gallic acids and are mostly present in the form of glucosides and some esters with glucose. However, gallic acid is mainly esterified to quinic acid or catechins and usually present in polymeric forms as soluble tannins [21]. HCAs are found in a variety of foods, the most common being caffeic and ferulic acids and their derivatives. They are mostly present in ester forms bound to quinic, shikimic, or tartaric acids. Caffeic acid is generally the most abundant phenolic acid and is mainly found as the quinic ester, chlorogenic acid, in blueberries, kiwis, plums, and apples [23]. However, very high intake of chlorogenic acid is common among coffee drinkers because of very high concentrations (50-150 mg of chlorogenic acids in one cup $(200 \mathrm{~mL})$ of instant coffee [24] (Figure 1).

Stilbenes possess a 1,2-diarylethenes structure based on the $\mathrm{C}_{6}-\mathrm{C}_{2}-\mathrm{C}_{6}$ backbone and are usually synthesized in plants in response to infection or injury [25]. Resveratrol, the main stilbene, can be found in the cis or trans configurations, either glucosylated (piceid) or in lower concentrations as the parent molecule of a family of polymers such as viniferins, pallidol, or ampelopsin A [26]. Major dietary sources of resveratrol include grapes, wine, and peanuts. Resveratrol is found in low concentrations $(0.3-7 \mathrm{mg}$ aglycones/L and $15 \mathrm{mg}$ glycosides/L) in red wine, and thus it seems unlikely to produce protective effects at normal nutritional intakes (Figure 1).

\section{Brain Localisation of Polyphenols}

Despite the increasing amount of evidence for the bioavailability of polyphenols in the systemic circulation [22, 2729] only little information is available regarding their ability to reach the central nervous system (CNS). In order for polyphenols to access the brain, they must first cross a tightly regulated, selectively permeable endothelial cell layer which isolates the CNS tissue from the vasculature, the bloodbrain barrier (BBB). The BBB is permeable to nutrients and actively excludes many substances from the central nervous system [30]. Using in vitro models, initial studies have demonstrated that polyphenols permeation through the BBB is dependent on the degree of lipophilicity of each compound with less polar polyphenols or metabolites (i.e., $\mathrm{O}$-methylated derivatives) capable of greater brain uptake than the more polar ones (i.e., sulfated and glucuronidated derivatives) [31]. Their brain entry will also depend on their interactions with efflux transporters, such as P-glycoprotein (Pgp) [32] and their stereochemistry. For example, both catechin and epicatechin could cross a cellular model of BBB in a time-dependent and stereoselectivity manner with epicatechin $\gg$ catechin [33]. The amount of nutrient or drug that 


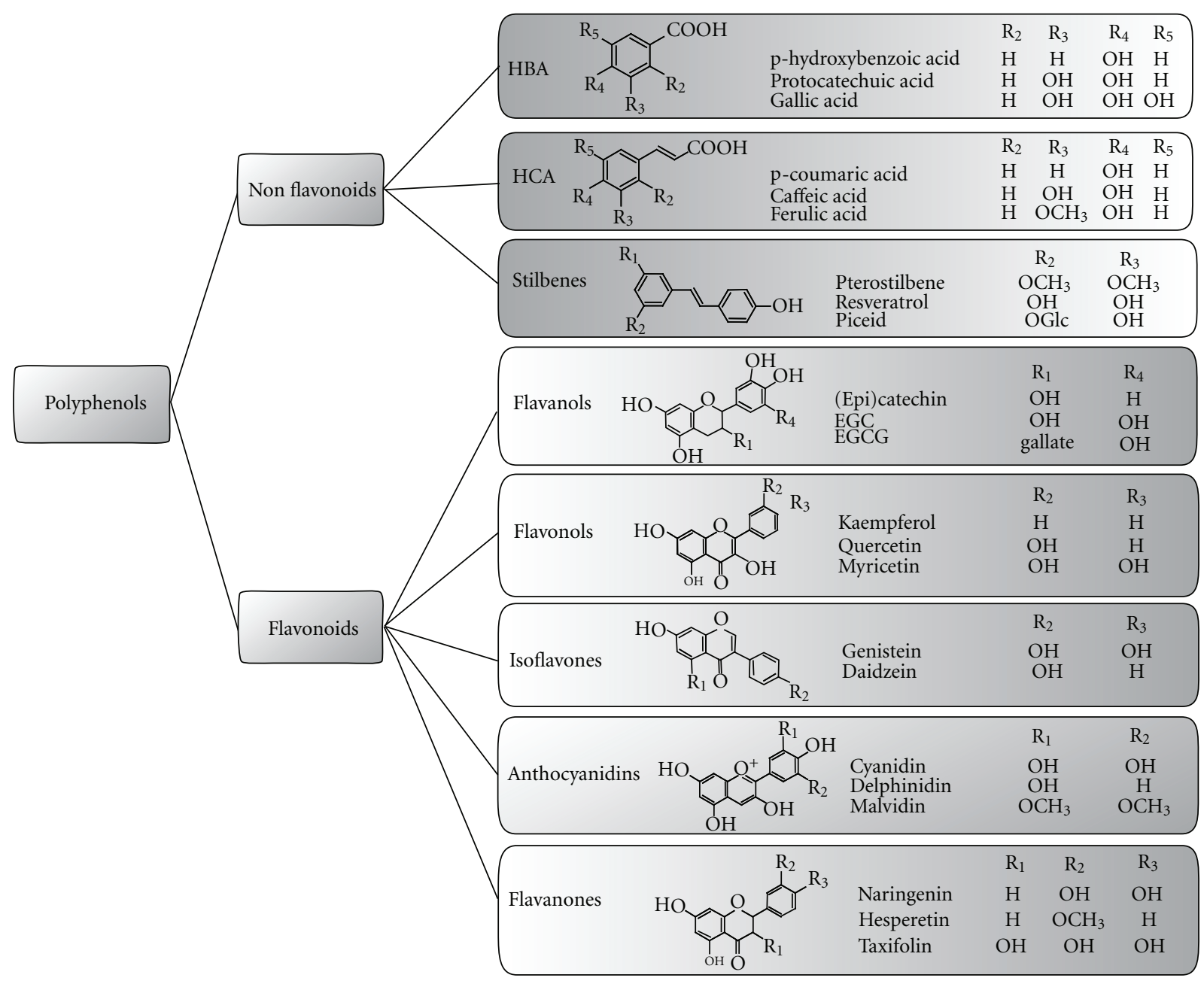

FIGURE 1: Structures of polyphenols. Polyphenols are a group of naturally occurring phytochemicals which are present in high amounts in fruits, vegetables, and natural products and are characterised by the presence of multiple hydroxyl groups on aromatic rings. These compounds are divided into two main categories, the flavonoids and non flavonoids, based on the number of phenol rings and the way in which these rings interact. For the flavonoid group, the major differences between the individual groups arise from the hydroxylation pattern of the ring-structure, the degree of saturation of the C-ring, and the substitution of the 3-position. HBAs, hydroxybennzoic acids; HCAs, hydroxycinammic acids.

penetrate into the brain was also investigated in vivo, with animal studies indicating that polyphenols are able to cross the BBB and to colocalise within the brain tissues independently of their route of administration. For example, naringenin was found in the brain following its intravenous administration [34], whilst epigallocatechin gallate [35], epicatechin [36], and anthocyanins [37, 38] were observed after oral administration. Although the uptake and distribution of dietary polyphenols within the brain are well documented, the question of the dose reaching the target tissues remains uncertain. Discrepancies in the findings mainly stem in the fact that studies reporting polyphenol brain uptake and concentrations often disregard residual blood as a potential confounder. Studies using exsanguinated, perfused animals or applying the recently published mathematical correction model [39] may therefore be more suitable for assessing polyphenol uptake and metabolism in the brain. Data deriving from such studies suggest that polyphenols usually localise in the brain at levels below $1 \mathrm{nmol} / \mathrm{g}$ tissue (see review by Schaffer and Halliwell [40]). Furthermore, several polyphenols have been identified in different regions of the rat $[38,41]$ and pig brains $[42,43]$ and usually accumulates in a nonregion-specificic manner [16, 44]. For example, recently, Janle et al. demonstrated that ${ }^{14} \mathrm{C}$-labelled grape polyphenols did not show any regional differences in ${ }^{14} \mathrm{C}$ accumulation from anterior to posterior slices of the brain [44]. Collectively, these results indicate that polyphenols transverse the $\mathrm{BBB}$ and localise within the brain tissue, suggesting that they are candidates for direct neuroprotective and neuromodulatory actions. Nonetheless, our knowledge regarding polyphenol absorption, metabolism, tissue distribution, and intracellular accumulation and excretion remains insufficient, and future work is needed to better understand their biological effects. 


\section{Effect of Polyphenols on Memory, Learning, and Neurocognitive Performance}

Accumulating evidence suggests that diet and lifestyle can play an important role in delaying the onset or halting the progression of neurodegenerative diseases and improving cognitive function [45-48]. With regards to diet, polyphenols have been associated with a reduced risk of developing dementia $[45,49]$, an improved cognitive performance in normal ageing [48] and an improved cognitive evolution [5]. More recently, high total polyphenol intake was also associated with better language and verbal memory but not with executive functioning. In particular, intake of catechins, theaflavins, flavonols, and hydroxybenzoic acids was positively associated with language and verbal memory, especially with episodic memory as assessed by the RI-48 test [50]. Although a positive correlation between dietary polyphenol consumption and cognitive decline has been mostly reported, a limited body of evidence is, however, suggestive that carrier of the APOE4 genotype may influence the beneficial effect of polyphenols in relation to dementia and AD. For example, the frequent consumption of fruits and vegetables was associated with a decreased risk of all cause dementia (hazard ratio [HR] $0.72,95 \%$ CI 0.53 to 0.97 ) especially amongst the APO\&4 noncarriers [51]. The relationship between polyphenols intake and $A P O \varepsilon$ genotype is intriguing, and further work is required to gain a better understanding of the physiological and molecular mechanisms underlying such disparity.

Over the last years, there has been much interest in the neurocognitive effects of berries, in reversing age-related deficits in motor function and spatial working memory $[14,16,52]$. While the consumption of cranberry juice over a 6 weeks period in older adults has failed to report any cognitive benefits [53], consumption of both grape or blueberry juices in older adults with or without mild cognitive impairment (MCI) reported significant improvement in memory function after 12 weeks intervention $[54,55]$. In addition to spatial memory, blueberry supplementation in aged animals has also been shown to improve "object recognition memory" [56] and "inhibitory fear conditioning learning" [57, 58]. Blueberry appears to have a pronounced effect on shortterm memory [58] and has also been shown to improve long-term reference memory following 8 weeks of supplementation. [14]. Tests using a radial arm maze have supported these findings and have provided further evidence for the efficacy of blueberries [16]. Indeed, these have shown that improvements in spatial memory may emerge within 3 weeks, the equivalent of about 3 years in humans. Although not fully understood, evidence suggest that blueberryderived polyphenols may enhance the efficiency of spatial memory by indirectly acting on the dentate gyrus (DG), an hippocampal subregion particularly sensitive to the effects of aging [59]. In particular, blueberry supplementation has been shown to significantly increase the precursor cells in the DG of aged rats [14]. Such link between hippocampal neurogenesis, cognitive performance, and aging may represent a potential mechanism by which polyphenol-derived foods may improve memory [60].
In addition to those with berries, human and animal studies with cocoa and tea flavanols have also provided further evidence that dietary polyphenols are beneficial in reversing the course of neuronal and behavioural aging $[7,61]$. For example, two recent acute human studies have shown that cocoa flavanol consumption was able to improve working memory and attention [12, 13]. In addition, pure (-)-epicatechin $(500 \mu \mathrm{g} / \mathrm{g})$ was also observed to enhance the retention of mice spatial memory, especially when combined with exercise [62], suggesting that polyphenols may be causal agents in inducing the behavioural effects. Although the exact mechanisms underlying such behavioural changes remain to be elucidated, evidence suggests that flavanol-rich foods improve peripheral blood flow and surrogate markers of cardiovascular function [63-65]. In addition, CNS imaging studies in humans have demonstrated that the consumption of flavanol-rich cocoa may improve cerebral blood flow (CBF) in healthy older adults [66] and in young adults in response to a cognitive task [67]. These effects are particularly significant, as increased cerebrovascular function is known to facilitate adult neurogenesis [68] and to enhance vascularisation $[69,70]$, two events important in the maintenance of cognitive performances.

The flavonoid-rich plant extract, Ginkgo biloba, has also been shown to induce positive effects on memory, learning, and concentration [71, 72]. Ginkgo biloba has a prominent effect on brain activity and short-term memory in animals and humans suffering from cognitive impairment $[11,73]$ and promotes spatial learning in aged rodents $[74,75]$. However, the pharmacological mechanisms by which Ginkgo biloba promotes cognitive effects remain unclear, although its ability to elicit a reduction in levels of reactive oxygen species (ROS) [76], to increase cerebral blood flow [77], to modulate membrane fluidity [78], to interact with muscarinic cholinergic receptors [79], to protect the striatal dopaminergic system [80], and to upregulate AMPA, calcium and chloride channels, and growth hormones [81] have been suggested as possible mechanisms underlying its actions in the CNS. Together, these data provide a strong indication that regular polyphenol consumption may have a positive effect on neurocognitive performance as we age (Figure 2).

\section{Polyphenol Protection against Neuronal Injury Induced by Neurotoxins}

There are a number of epidemiological studies which suggest that plant-derived polyphenol-rich foods or supplements might delay the initiation and progression of $\mathrm{AD}, \mathrm{PD}$, and related neurodegenerative disorders $[5,82]$. With regard to $\mathrm{AD}$, most of the preclinical studies of the effects of polyphenols have focused on models where there is increased production of beta-amyloid $(\mathrm{A} \beta)$, a small protein produced by the enzymatic cleavage of amyloid precursor protein (APP) [83]. For example, the chronic consumption of ferulic acid with the drinking water protected mice from the deleterious effects of an intracerebral injection of $\beta$-amyloid peptide [84]. More recently, using transgenic mouse models, studies have started to address the potential effect of polyphenol-rich diets on AD. Oral administration of 


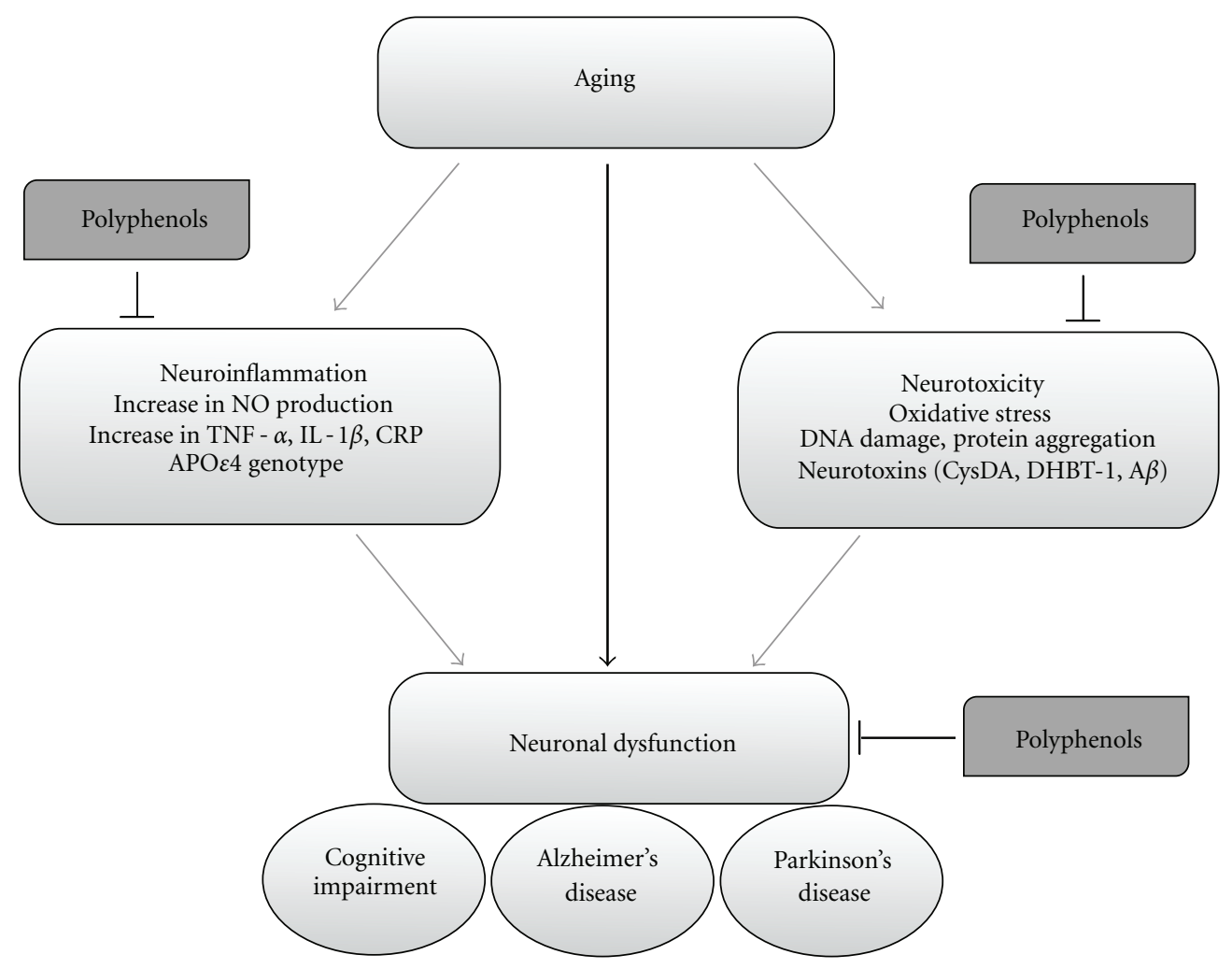

FIGURE 2: Modulation of neuronal dysfunction by dietary polyphenols. In ageing and neurodegenerative diseases, neuronal death can be triggered by specific genetic mutations, neurotoxins, and/or neuroinflammation. Initiating factors promote cellular alterations, including increases in oxidative stress, protein aggregation, DNA damage, and activation of apoptotic cascades. Dietary polyphenols have been observed to protect the brain against such cellular alteration through the modulation of neuronal function against endogenous neurotoxins and inhibition of glial-induced neuroinflammation. A $\beta$, amyloid beta; CysDA, 5-S-cysteinyldopamine; DHBT1, dihydrobenzothiazine 1; TNF- $\alpha$, tumor necrosis factor alpha; IL-1 $\beta$, interleukine-1 beta; CRP, C reactive protein; NO, nitric oxide.

epigallocatechin-3-gallate (EGCG) for 6 months in mice which overexpress the Swedish mutation of APP (APPsw), reduced $A \beta$ pathology and improved cognition [85]. Similarly long-term green tea catechin administration also improved spatial learning and memory in senescence prone mice, by decreasing $\mathrm{A} \beta_{1-42}$ oligomers and upregulating synaptic plasticity-related proteins in the hippocampus [86]. The antiamyloidogenic activity is not unique to EGCG and a number of other polyphenols bind to $\mathrm{A} \beta$ fibrils and prevent further fibrillization [87-89]. For example, gallic acid and catechin-rich grape seed polyphenolic extract (GSPE) inhibited cognitive deterioration coincident with reduced levels of soluble high molecular weight oligomers of $\mathrm{A} \beta$ [88]. Repeated intraperitoneal injection of nobiletin has similar effects [90]. The mechanisms underlying these changes are not clear but might be linked to increased nonamyloidogenic processing of APP, through stimulating the activity of $\alpha$ secretase, which cleaves APP at a site which prevents the formation $A \beta$ species $[91,92]$. Alternatively, it is conceivable that polyphenols reduce $\mathrm{A} \beta$ plaque pathology by inhibiting amyloid aggregation and fibrillization either as a result of metal chelation activity [93-95] or by favouring the formation of nontoxic oligomers [96]. Additional mechanisms have been also suggested for the ability of polyphenols to delay the initiation of and/or slow the progression of AD-like pathology, including a potential to inhibit neuronal apoptosis triggered by neurotoxic species (e.g., oxidative stress and neuroinflammation) or disrupt amyloid $\beta$ aggregation and effects on amyloid precursor protein processing through the inhibition of $\beta$-secretase (BACE-1) [97] and/or activation of $\alpha$-secretase (ADAM10) (See review by Williams and Spencer [98]).

The potential utility of polyphenols in neurodegeneration extends beyond $\mathrm{AD}$, and there is also considerable interest in their therapeutic potential in $\operatorname{PD}[47,99]$. There is good evidence to suggest that the consumption of green tea may have a beneficial effect in reducing the risk of PD [82], as has been extensively reviewed elsewhere $[100,101]$. The efficacy of green tea is likely to be mediated by the effects of EGCG, which has been shown to attenuate the selective degeneration of dopamine neurons in animal models of PD induced by toxins including 6-hydroxydopamine [102] and MPTP [103]. In addition, the citrus flavonoid tangeretin has also been observed to be neuroprotective against 6-hydroxydopamine lesioning in a rat model of PD [17]. In vitro studies have also indicated that polyphenols might act to prevent PD pathology via their ability to prevent the formation of the endogenous neurotoxin, 5-S-cysteinyl-dopamine 
(CysDA) $[104,105]$. Such adducts may be generated by reactive species [105] and have been observed to be elevated in the human substantia nigra of patients who died of PD [104], suggesting that such species may be potential endogenous nigral toxins. However, CysDA-induced neuronal injury is counteracted by nanomolar concentrations of various polyphenols including pelargonidin, quercetin, hesperetin, caffeic acid, tyrosol, $p$-coumaric acid, and the $4^{\prime}-\mathrm{O}$-Me derivatives of catechin and epicatechin $[105,106]$. Furthermore, in presence of the flavanol, (+)-catechin, tyrosinase-induced formation of CysDA was inhibited by a mechanism linked to the capacity of catechin to undergo tyrosinase-induced oxidation to yield cysteinyl-catechin adducts [107]. In contrast, the inhibition afforded by flavanones, such as hesperetin, was not accompanied with the formation of cysteinyl-hesperetin adducts, indicating that it may be inhibited via direct interaction with tyrosinase [107]. Furthermore, the stilbene resveratrol also had a small inhibitory effect; however, its reaction with tyrosinase in the presence of L-cysteine led to the formation of dihydrobenzothiazine (DHBT-1) [107], a strong neurotoxin known to selectively inhibit the respiratory chain complex I, the alpha-ketoglutarate dehydrogenase (alpha-KGDH), and the pyruvate dehydrogenase complexes (PDHC) [108] (Figure 2). Collectively, these studies suggest that polyphenols have the potential to confer benefit in diverse neurodegenerative disorders. Some of the major neuroprotective mechanisms are discussed in more detail below.

\section{Role of Polyphenols in Preventing Neuroinflammation}

Although neuroinflammation plays a critical role in brain host defence, it also contributes to the underlying neuronal loss in neurodegenerative disorders, such as PD, AD [109111] and to damages associated with cerebral ischemia [112]. Neuroinflammation is "driven" by activated resident glial cells (astrocytes and microglia) which result in invasion of circulating immune cells and the production of proinflammatory cytokines (TNF- $\alpha$, IL- $1 \beta$, and IL-6), nitric oxide $\left(\mathrm{NO}^{\bullet}\right)$, prostaglandin $\mathrm{E} 2$, chemokines, and reactive oxygen species (ROS). Amongst the numerous factors released by activated glial cells, excessive $\mathrm{NO}^{\bullet}$ production has been reported to induce neuronal cell death by damaging the mitochondrial electron transport chain function in neurons [113] therefore resulting in neuronal ATP synthesis disruption and in increased generation of ROS [114]. Furthermore, NADPH oxidase activation, an important event in activated microglia-induced neurotoxicity, has also been suggested to mediate both superoxide $\left(\mathrm{O}_{2}{ }^{\bullet-}\right)$ production and to release proinflammatory molecules such as TNF- $\alpha$ [115]. NO ${ }^{\bullet}$ produced in microglia or astrocytes may react with $\mathrm{O}_{2}{ }^{\bullet-}$, produced by NADPH oxidase $[116,117]$, to generate the neurotoxic peroxynitrite radical $\left(\mathrm{ONOO}^{-}\right)[116]$. $\mathrm{ONOO}^{-}$has been observed to inhibit mitochondrial respiration, induce caspase-dependent neuronal apoptosis, and to induce glutamate release resulting in excitotoxicity and neuronal death $[116,118]$. Additionally, glial cytokine production may also play a deleterious role in neurodegenerative diseases by binding to specific cell surface receptors expressed in neurons and activating apoptotic pathways. For example, TNF- $\alpha$ binds to the tumour necrosis factor receptor-1 (TNFR1) which may lead to neuronal apoptosis $[119,120]$.

Since long-term use of nonsteroidal anti-inflammatory drugs (NSAIDs) has been shown to lower the risk of AD in later life [121], there has been much interest in the development of new drugs capable of preventing neuroinflammatory-mediated brain injury. Emerging evidence suggests that dietary polyphenols may exert neuroprotective effects by suppressing the activation of microglia, which mediates inflammatory processes in the CNS. Although rather complex, the main anti-inflammatory properties of polyphenols include: (1) an inhibitory role on the release of cytokines, such as IL- $1 \beta$ and TNF- $\alpha$, from activated glia; (2) an inhibitory action against iNOS induction and subsequent nitric oxide production in response to glial activation; (3) an ability to inhibit the activation of NADPH oxidase and subsequent ROS generation in activated glia; (4) a capacity to downregulate the activity of proinflammatory transcription factors such as NF- $\kappa \mathrm{B}$ through their influences of a number of glial and neuronal signaling pathways, such as MAPK cascade (discussed in details below) [122, 123].

For example, the commonly consumed flavonol quercetin has been reported to inhibit neuroinflammation by attenuating nitric oxide production and iNOS gene expression in microglia $[117,124]$ and by preventing inflammatory cytokine production, thus preventing neuronal injury [125, 126]. However, one of the major physiological metabolites of quercetin, quercetin- $3^{\prime}$-sulfate, failed to demonstrate any anti-inflammatory action [117]. Nevertheless, these studies have employed quercetin concentrations (10-50 $\mu \mathrm{M})$ much higher than of those found in plasma after ingestion [28]. In contrast to this, epicatechin and catechin (10-300 nM) were observed to inhibit TNF- $\alpha$ release but not iNOS expression or nitric oxide production in primary glial cells [127] suggesting that flavanols at physiologically relevant concentrations may hold the potential to exert anti-inflammatory effects in the central nervous system. Polyphenols present in blueberry have also been reported to inhibit $\mathrm{NO}^{\circ}$, IL- $1 \beta$ and TNF- $\alpha$ production in activated microglia cells [128], and the flavanone naringenin was observed to be highly effective in reducing LPS/IFN- $\gamma$-induced glial cell activation [127]. Dietary polyphenols are also potent inhibitors of NADPH oxidase activity in vitro. A study comparing 45 polyphenolic compounds indicated that whilst both the flavanols $(+)$ catechin and (-)-epicatechin failed to inhibit NADPH oxidase, their relevant methylated metabolites exhibited strong NADPH oxidase inhibition through an apocynin-like mechanism [129]. Interestingly, other apocynin-like phenolic compounds, such as, ferulic acid, homovanillin alcohol, caffeic acid, tyrosol, and vanillic acid were also observed to inhibit NADPH oxidase activity, therefore indicating that smaller polyphenols, more structurally related to some colonic metabolites, may also serve as novel therapeutic agents in neuroinflammation (Figure 2).

There is also data which shows encouraging positive effects of polyphenols in animal and in vitro models relevant to multiple sclerosis (MS), a chronic debilitating disease which is characterised by demyelination, progressive 
irreversible axonal damage and inflammation [130]. For example, EGCG delivered orally reduces symptom severity in the autoimmune encephalomyelitis model of relapsingremitting MS by reducing inflammation and increasing neuroprotection [131]. Quercetin has also been reported to be effective in the Experimental Autoimmune Encephalomyelitis (EAE) mouse model, and reduces T-cell proliferation in vitro at concentrations exceeding $10 \mu \mathrm{M}$ [132]. Micromolar concentrations of luteolin, apigenin, fisetin, and quercetin (but not morin or hesperetin) were reported to suppress the production of the cytokine interferon-gamma (IFN $\gamma$ ) from lymph-node-derived $\mathrm{T}$ cells but, paradoxically, worsen clinical severity in the EAE model. More recently, resveratrol protection against EAE was associated with rises in IL-17/IL10 and with repressed macrophage IL- 6 and IL-12/23 p40 expression [133]. Thus, the studies to date show promising proof of concept of beneficial effects of polyphenols in suppressing immune and inflammatory responses in models of MS.

\section{Mechanisms Underpinning the Beneficial Effects of Polyphenols}

It has generally been assumed that the health benefits of polyphenols were linked to their capacity to directly scavenge free radicals and other nitrogen species in vitro [134-137]. However, the concentrations at which they exert such antioxidant activity are unlikely to be easily achieved in vivo as many polyphenols have very limited bioavailability and are extensively metabolised therefore reducing their antioxidant potential [19]. During the last years, a new realisation of how nutritional antioxidants may function has been envisaged, and recent findings have suggested that in lower amounts, typical of those attained in the diet, polyphenols may activate one or more adaptive cellular stress responses pathways [93, 138-140]. Activation of such hormetic pathways in neurons results in the production of several types of cytoprotective proteins including neurotrophic factors, protein chaperones, antioxidant and phase II enzymes, and antiapoptotic proteins $[141,142]$. One particular protective pathway which is receiving considerable attention in regard to hormesis in the nervous system involves the transcription factor NF-E2related factor-2 (Nrf2). Nrf2 binds to the antioxidant-responsive element (ARE) with high affinity and plays a central role in the upregulation of genes implicated in the regulation of the cellular redox status and the protection of the cell from oxidative insult $[143,144]$. Under basal conditions, Nrf2 interacts with a cytosolic repressor protein Keap1 (Kelch $\mathrm{ECH}$ associating protein) limiting Nrf2-mediated gene expression [145]. In cells exposed to oxidative stress, Nrf2 is released from Keap1 and translocates to the nucleus, where it activates ARE-dependent transcription of phase II and antioxidant defence enzymes, such as glutathione-S-transferase (GST), glutathione peroxidase (GPx), and heme oxygenase-1 (HO-1) [146].

Most polyphenols have been reported to respond in a bell-shaped dose-response manner, presenting cellular toxicity at high concentrations while inducing light chemical stress at lower doses with activation of physiological hormesis in cells [142], resulting in overexpression of defensive genes such as those activated by Nrf2. For example, resveratrol was observed to protect $\mathrm{PC} 12$ cells against $\mathrm{H}_{2} \mathrm{O}_{2}$ mediated oxidative stress [147] and to attenuate cerebral ischemic injury in rat [148] via the activation of Nfr2 and the upregulation of HO-1. The caffeic acid phenethyl ester (CAPE), the active component of propolis, protected nigral dopaminergic neurons in an experimental mouse model of dopaminergic neurodegeneration through the modulation of heme oxygenase- 1 and brain-derived neurotrophic factor (BDNF) [149]. The ethyl ferulate (EFE), a lipophilic polyphenol also found in propolis, was observed to protect rat neurons against oxidative stress via the induction of $\mathrm{Nrf} 2 /$ HO-1 [150]. The flavanol (-)-epicatechin prevented stroke damage through the Nrf2/HO1 pathway [151], and increased glutathione levels in primary astrocytes through an upregulation of ARE-mediated gene expression [152]. Although a positive correlation between dietary polyphenol consumption and brain function has been mostly reported, evidence is also suggestive that $A P O \varepsilon 4$ carriers may not benefit from the frequent consumption of fruits and vegetables rich in such phytochemicals. Indeed, previous findings suggest that $A P O \varepsilon 4$ carriers are less responsive towards the anti-inflammatory, paraoxanase-1 inducing, and blood pressure lowering activity of quercetin [153-155]. Such diminished responsiveness of the $A P O \varepsilon 4$ versus $A P O \varepsilon 3$ genotype (approximately $55-60 \%$ of the Caucasians population are homozygotes for the $\varepsilon 3$ allele) may be attributed to an impaired Nrf2 signalling and to a lower activity of Nrf2 target genes including glutathione-S-transferase, heme oxygenase-1, and $\mathrm{NAD}(\mathrm{P}) \mathrm{H}$ dehydrogenase, quinone 1 [156].

Several upstream signaling cascades may either individually, or in a combined manner, activate Nrf2. These include selective actions on a number of protein kinase and lipid kinase signalling cascades, most notably the PI3K/Akt and MAP kinase pathways which regulate prosurvival transcription factors and gene expression [19]. In general, in vitro studies have reported that polyphenols, at submicromolar concentrations, activate ERK, as determined by measuring increased phosphorylation of this enzyme. For example, both the flavanol (-)-epicatechin $(0.1$ and $0.3 \mu \mathrm{M})$ [139] and the citrus flavanone hesperetin at nanomolar concentrations [140] were observed to activate ERK1/in cortical neurons. Furthermore, EGCC was reported to restore ERK1/2 activities in 6-hydroxydopamine-treated or serum-deprived neurons [102]. ERK activation often leads to the activation of CREB, a transcription factor considered to be critical in the induction of long-lasting changes in synaptic plasticity and memory $[157,158]$. CREB activation regulates the expression of a number of important genes, including BDNF, thus playing a pivotal role in controlling neuronal survival and synaptic function in the adult central nervous system [159, 160]. Regulation of BDNF is of particular interest as it is linked with the control of synaptic plasticity and longterm memory [161], and recent studies have shown that spatial memory performance in rats supplemented with blueberry correlates well with the activation of CREB and with increases of BDNF in the hippocampus [58]. Fisetin, 


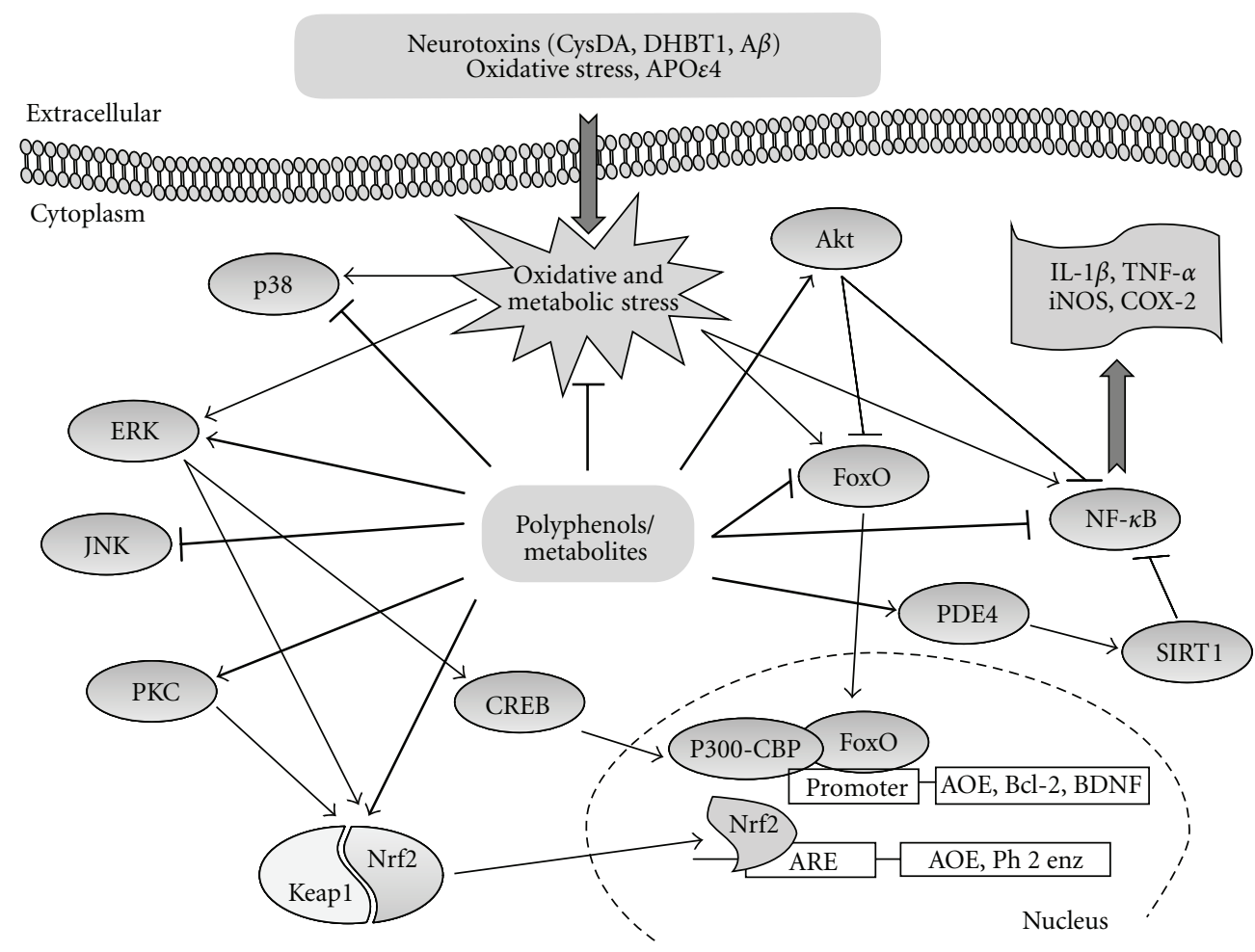

FIGURE 3: Mechanisms underlying the biological effects of polyphenols. Polyphenols and their in vivo metabolites activate cellular stressresponse pathways resulting in the upregulation of neuroprotective genes. For example, both PKC and ERK can activate the nuclear factor erythroid 2-related factor 2 (Nrf2). Nrf2 then translocates to the nucleus and binds to the antioxidant response element (ARE) in genes that encode cytoprotective proteins such as antioxidant enzymes (AOE) and phase 2 (Ph2) enzymes. The transcription factor cAMP-responseelement-binding protein (CREB) is also activated by ERK, which induces the expression of brain-derived neurotrophic factor (BDNF), a mediator of neurohormesis. In addition, polyphenols can also regulate the transcription factor NF- $\kappa \mathrm{B}$, which can mediate adaptive cellular stress responses by reducing the expression of inflammatory cytokines. Activated SIRT1 may also inhibit NF- $\kappa \mathrm{B}$ and so can reduce the cellular stress response. Another important pathway activated by metabolic and oxidative stress involves transcription factors of the forkhead (FoxO) family, which modulate genes that encode antioxidant enzymes and other stress-response proteins.

a polyphenol found in strawberries, has also been shown to improve long-term potentiation and to enhance object recognition in mice by a mechanism dependent on the activation of ERK and CREB [162].

As well as effects on the ERK/CREB/BDNF axis, polyphenols are also known to modulate the activity of an enzyme system associated with neuroprotection, Akt (also known as $\mathrm{PKB})$. One of the major enzymes which controls Akt/PKB activity is the lipid kinase, PI3K. In cortical neurons, polyphenols such as the citrus flavanone hesperetin ( 0.1 and $0.3 \mu \mathrm{M})$ cause the activation of $\mathrm{Akt} / \mathrm{PKB}$ and the consequent inhibition of proteins associated with cell death such as apoptosis signal-regulating kinase 1 (ASK1), Bad, caspase-9 and caspase-3 [140]. The activation of Akt by flavonoids in hippocampal neurons has been shown to trigger the increased translation of specific mRNA subpopulations [163], including the activity-regulated cytoskeletal-associated protein (Arc/Arg3.1) [58]. Arc is also under the regulatory of control of both BDNF [164] and ERK signalling [165]. Increased Arc expression may facilitate changes in synaptic strength, and the induction of morphological changes in dendritic spines [166]. In support of this, studies have indicated that changes in neuronal morphology occur in response to flavonoid supplementation [8], and that certain polyphenols can influence neuronal dendrite outgrowth in vitro [167-169].

In addition to the previously described signalling systems, two additional pathways that are known to play important roles in neuronal stress adaptation are those involving the transcription factor NF- $\kappa \mathrm{B}$ and the protein sirtuin-1 (SIRT1) [170]. In neurons activation of NF- $\kappa$ B can prevent cell death induced by a range of insults including exposure to excitotoxins and oxidative stress [171]. Numerous polyphenols have been shown ascribe to inhibit NF- $\kappa \mathrm{B}$ in different cell types. For example, quercetin $(50 \mu \mathrm{M})$ suppresses NF- $\kappa \mathrm{B}$ in a microglial cell line [117]. Apigenin $(5-15 \mu \mathrm{M})$ blocks LPS stimulation of the NF- $\kappa$ B pathway in RAW 246.7 macrophages and reduces $\kappa \mathrm{B}$-transcriptional activity [172]. Catechin $(0.13-2 \mathrm{mM})$ has been reported to increase mouse microglial cell survival following exposure to the oxidative agent tert-butylhydroperoxide (tBHP) by suppressing NF- $\kappa$ B activation [173]. The flavone wogonin $(50 \mu \mathrm{M})$ was shown to reduce NF- $\kappa \mathrm{B}$ activation in C6 glioma cells and prevent microglial activation [174], and baicalein is reported to inhibit NO. Production in and NF- $\kappa$ B activity in microglia [175, 176]. Although these data give proof of principle that NF- $\kappa B$ is a potential target of polyphenols, the concentrations 
required for positive effects of those particular compounds in vitro are supraphysiological and difficult to be achieved through the diet. While it is likely that the antioxidant effects of the polyphenols used in those studies account for the positive effects on suppressing NF- $\kappa \mathrm{B}$ activation, at dietary relevant concentrations $(0.1-1 \mu \mathrm{M})$, different classes of polyphenol were unable to suppress NF- $\kappa \mathrm{B}$-signaling pathways in primary astrocytes [177]. Despite the fact that polyphenols may be effective compounds at suppressing neuroinflammation in vitro, the NF- $\kappa \mathrm{B}$ signalling system is unlikely to be regarded as the primary signalling system responsible for their effects in vivo.

The protein SIRT1 can also be activated by polyphenols resulting in cell proliferation and cell survival. Cellular substrates of SIRT1 include the tumor suppressor p53, the transcription factor $\mathrm{NF}-\kappa \mathrm{B}$, the forkhead box class $\mathrm{O}$ (FoxO) family of transcription factors, the peroxisome proliferatoractivated receptor (PPAR) $-\gamma$, the PPAR- $\gamma$ coactivator $1 \alpha$ (PGC-1 $\alpha$ ), and endothelial nitric oxide synthase (eNOS) [178]. In the realm of polyphenols, resveratrol has been the most extensively studied for its ability to modulate SIRT1 both in vivo and in vitro $[179,180]$. However, the observed activation of SIRT1 by resveratrol in vitro now appears to be an artefact of the assay used, therefore raising doubt on the direct resveratrol-SIRT1 connection [181]. Recently, further insight into the mechanisms by which resveratrol interact with sirtuins has been proposed. Using a model of agedrelated metabolic phenotype, Park et al. identified phosphodiesterase (PDE) enzymes as direct targets and proposed that resveratrol indirectly activates SIRT1 through a signaling cascade involving cAMP, Epac1, and AMPK [182]. Although these results provide important new mechanisms by which resveratrol interacts with sirtuins, the supraphysiological dose used in these experiments must be taken with caution when translating these results to in vivo dietary intervention. SIRT1 also plays an important role in the regulation of neurodegenerative disorders [183], and several findings have now converged on the notion that activation of sirtuins by polyphenols could be extended to degenerating neurons. For example, resveratrol, was observed to protect both C. elegans and mouse neurons against the cytotoxicity of the mutant polyglutamine protein huntingtin through a mechanism involving Sir-2.1 and SIRT1 activation, respectively [184]. Furthermore, resveratrol decreased cell death associated with neurons cultured from a mutant huntingtin (109Q) knock-in mice, in a manner that is reversible by two SIRT1 inhibitors, sirtinol and nicotinamide [183]. Finally, overexpression of SIRT1 and resveratrol treatment markedly reduced NF- $\kappa \mathrm{B}$ signaling stimulated by $\mathrm{A} \beta$ and had strong neuroprotective effects, therefore linking SIRT1-NF- $\kappa$ B activity to AD [185] (Figure 3).

\section{Conclusion}

The neuroprotective actions of dietary polyphenols involve a number of effects within the brain, including a potential to protect neurons against injury induced by neurotoxins, an ability to suppress neuroinflammation, and the potential to promote memory, learning, and cognitive function. While many of the mechanisms underpinning their beneficial effects remain to be elucidated, it has become clear that they in part involve decreases in oxidative/inflammatory stress signaling increases in protective signaling, and may also involve hormetic effects to protect neurons against oxidative and inflammatory stressors. Most of the dietary polyphenols that have been shown to be protective against age-related disease are all chemically reactive and nearly all are electrophilic. Such chemical features renders these molecules capable of influencing the redox potential of their target cells and to modulate series of transcriptions factors that result in the activation of phase I and phase II metabolism genes. Nonetheless, much of the data obtained on their bioactivity derived from short-term basis in vitro or in vivo studies where the dose used was not of nutritional relevance. Although at the moment, the balance of evidence that does suggest that polyphenol effects contribute to the benefits of a high intake of fruits and vegetables, the extent of their contribution in vivo, and at physiological relevant concentrations remains uncertain. More work needs to be done to prove whether this class of compounds is most likely to result in health benefits and to determine their beneficial effects in slowly developing neurodegenerative disorders. In view of their multiple biological activities, the consumption of polyphenol-rich foods throughout life holds a potential to limit neurodegeneration and to prevent or reverse age-dependent deteriorations in cognitive performance. However, the therapeutic and pharmacological potential of these natural compounds still remains to be translated in humans in clinical conditions. Moreover, efficacy in RCT is also needed to support the relatively consistent epidemiological and mechanistic evidence. Despite this lack of efficacy data and the uncertainty of their effects in vivo, investigations into the absorption and metabolism of various polyphenols in humans indicate that there are common pathways for the metabolism of the majority of polyphenols, notably via their bacterial metabolism in the large intestine $[186,187]$. Consequently, research on developing dietary polyphenols for applications in neurodegenerative disorders should prioritise investigations of smaller polar polyphenols for brain bioavailability and bioactivity. The challenge ahead therefore is to proceed cautiously until rigorous randomized controlled clinical trials have been undertaken to determine empirically whether polyphenols and/or their metabolites have efficacy in individuals affected by dementia and other neurodegenerative conditions.

\section{References}

[1] WHO, Mediumterm strategic plan 2008-2013 and propopsed programme budget 2008-2009, Geneva, Switzerland, Word Health Organisation, 2007.

[2] K. A. Jellinger and C. Stadelmann, "Problems of cell death in neurodegeneration and Alzheimer's disease," Journal of Alzheimer's Disease, vol. 3, no. 1, pp. 31-40, 2001.

[3] A. Barzilai and E. Melamed, "Molecular mechanisms of selective dopaminergic neuronal death in Parkinson's disease," Trends in Molecular Medicine, vol. 9, no. 3, pp. 126-132, 2003. 
[4] T. L. Spires and B. T. Hyman, "Transgenic models of Alzheimer's disease: learning from animals," NeuroRx, vol. 2, no. 3, pp. 423-437, 2005.

[5] L. Letenneur, C. Proust-Lima, A. Le Gouge, J. F. Dartigues, and P. Barberger-Gateau, "Flavonoid intake and cognitive decline over a 10-year period," American Journal of Epidemiology, vol. 165, no. 12, pp. 1364-1371, 2007.

[6] K. Beking and A. Vieira, "Flavonoid intake and disabilityadjusted life years due to Alzheimers and related dementias: a population-based study involving twenty-three developed countries," Public Health Nutrition, vol. 13, no. 9, pp. 1403 1409, 2010.

[7] Y. C. Chan, K. Hosoda, C. J. Tsai, S. Yamamoto, and M. F. Wang, "Favorable effects of tea on reducing the cognitive deficits and brain morphological changes in senescenceaccelerated mice," Journal of Nutritional Science and Vitaminology, vol. 52, no. 4, pp. 266-273, 2006.

[8] A. M. Haque, M. Hashimoto, M. Katakura, Y. Tanabe, Y. Hara, and O. Shido, "Long-term administration of green tea catechins improves spatial cognition learning ability in rats," Journal of Nutrition, vol. 136, no. 4, pp. 1043-1047, 2006.

[9] T. Kaur, C. M. Pathak, P. Pandhi, and K. L. Khanduja, "Effects of green tea extract on learning, memory, behavior and acetylcholinesterase activity in young and old male rats," Brain and Cognition, vol. 67, no. 1, pp. 25-30, 2008.

[10] D. R. Oliveira, P. F. Sanada, F. A. C. Saragossa et al., "Neuromodulatory property of standardized extract Ginkgo biloba L. (EGb 761) on memory: behavioral and molecular evidence," Brain Research, vol. 1269, no. C, pp. 68-89, 2009.

[11] O. Shif, K. Gillette, C. M. Damkaoutis, C. Carrano, S. J. Robbins, and J. R. Hoffman, "Effects of Ginkgo biloba administered after spatial learning on water maze and radial arm maze performance in young adult rats," Pharmacology Biochemistry and Behavior, vol. 84, no. 1, pp. 17-25, 2006.

[12] D. T. Field, C. M. Williams, and L. T. Butler, "Consumption of cocoa flavanols results in an acute improvement in visual and cognitive functions," Physiology and Behavior, vol. 103, no. 3-4, pp. 255-260, 2011.

[13] A. B. Scholey, S. J. French, P. J. Morris, D. O. Kennedy, A. L. Milne, and C. F. Haskell, "Consumption of cocoa flavanols results in acute improvements in mood and cognitive performance during sustained mental effort," Journal of Psychopharmacology, vol. 24, no. 10, pp. 1505-1514, 2010.

[14] G. Casadesus, B. Shukitt-Hale, H. M. Stellwagen et al., "Modulation of hippocampal plasticity and cognitive behavior by short-term blueberry supplementation in aged rats," Nutritional Neuroscience, vol. 7, no. 5-6, pp. 309-316, 2004.

[15] B. Shukitt-Hale, F. C. Lau, A. N. Carey et al., "Blueberry polyphenols attenuate kainic acid-induced decrements in cognition and alter inflammatory gene expression in rat hippocampus," Nutritional Neuroscience, vol. 11, no. 4, pp. 172$182,2008$.

[16] C. M. Williams, M. A. El Mohsen, D. Vauzour et al., "Blueberry-induced changes in spatial working memory correlate with changes in hippocampal CREB phosphorylation and brain-derived neurotrophic factor (BDNF) levels," Free Radical Biology and Medicine, vol. 45, no. 3, pp. 295-305, 2008.

[17] K. P. Datla, M. Christidou, W. W. Widmer, H. K. Rooprai, and D. T. Dexter, "Tissue distribution and neuroprotective effects of citrus flavonoid tangeretin in a rat model of Parkinson's disease," NeuroReport, vol. 12, no. 17, pp. 3871-3875, 2001.

[18] S. Bastianetto, W. H. Zheng, and R. Quirion, "Neuroprotective abilities of resveratrol and other red wine constituents against nitric oxide-related toxicity in cultured hippocampal neurons," British Journal of Pharmacology, vol. 131, no. 4, pp. 711-720, 2000.

[19] R. J. Williams, J. P. E. Spencer, and C. Rice-Evans, "Flavonoids: antioxidants or signalling molecules?" Free Radical Biology and Medicine, vol. 36, no. 7, pp. 838-849, 2004.

[20] V. Calabrese, C. Cornelius, A. T. Dinkova-Kostova et al., "Cellular stress responses, hormetic phytochemicals and vitagenes in aging and longevity," Biochimica et Biophysica Acta, vol. 1822, no. 5, pp. 753-783, 2012.

[21] K. Herrmann, "Occurrence and content of hydroxycinnamic and hydroxybenzoic acid compounds in foods," Critical Reviews in Food Science and Nutrition, vol. 28, no. 4, pp. 315347, 1989.

[22] C. Manach, A. Scalbert, C. Morand, C. Rémésy, and L. Jiménez, "Polyphenols: food sources and bioavailability," American Journal of Clinical Nutrition, vol. 79, no. 5, pp. 727747, 2004.

[23] A. Fleuriet and J. Macheix, "Phenolic acids in fruits," in Flavonoids in Health and Disease, C. A. Rice-Evans and L. Packer, Eds., pp. 35-59, Marcel Dekker, New York, NY, USA, 1998.

[24] M. N. Clifford, "Chlorogenic acids and other cinnamatesnature, occurrence, dietary burden, absorption and metabolism," Journal of the Science of Food and Agriculture, vol. 80, no. 7, pp. 1033-1043, 2000.

[25] P. Langcake, "Disease resistance of vitis spp and the production of the stress metabolites resveratrol, epsilon-viniferin, alpha-viniferin and pterostilbene," Physiological Plant Pathology, vol. 18, no. 2, pp. 213-226, 1981.

[26] P. Langcake and R. J. Pryce, "The production of resveratrol and the viniferins by grapevines in response to ultraviolet irradiation," Phytochemistry, vol. 16, no. 8, pp. 1193-1196, 1977.

[27] A. Crozier, I. B. Jaganath, and M. N. Clifford, "Dietary phenolics: chemistry, bioavailability and effects on health," Natural Product Reports, vol. 26, no. 8, pp. 1001-1043, 2009.

[28] C. Manach, G. Williamson, C. Morand, A. Scalbert, and C. Rémésy, "Bioavailability and bioefficacy of polyphenols in humans. I. Review of 97 bioavailability studies," The American Journal of Clinical Nutrition, vol. 81, supplement 1, pp. 230S-242S, 2005.

[29] G. Williamson and C. Manach, "Bioavailability and bioefficacy of polyphenols in humans. II. Review of 93 intervention studies," The American Journal of Clinical Nutrition, vol. 81, no. 1, pp. 243S-255S, 2005.

[30] N. J. Abbott, A. A. K. Patabendige, D. E. M. Dolman, S. R. Yusof, and D. J. Begley, "Structure and function of the bloodbrain barrier," Neurobiology of Disease, vol. 37, no. 1, pp. 1325, 2010.

[31] K. A. Youdim, M. S. Dobbie, G. Kuhnle, A. R. Proteggente, N. J. Abbott, and C. Rice-Evans, "Interaction between flavonoids and the blood-brain barrier: in vitro studies," Journal of Neurochemistry, vol. 85, no. 1, pp. 180-192, 2003.

[32] K. A. Youdim, M. Z. Qaiser, D. J. Begley, C. A. Rice-Evans, and N. J. Abbott, "Flavonoid permeability across an in situ model of the blood-brain barrier," Free Radical Biology and Medicine, vol. 36, no. 5, pp. 592-604, 2004.

[33] A. Faria, D. Pestana, D. Teixeira et al., "Insights into the putative catechin and epicatechin transport across blood-brain barrier," Food and Function, vol. 2, no. 1, pp. 39-44, 2011.

[34] H. W. Peng, F. C. Cheng, Y. T. Huang, C. F. Chen, and T. H. Tsai, "Determination of naringenin and its glucuronide conjugate in rat plasma and brain tissue by high-performance 
liquid chromatography," Journal of Chromatography B, vol. 714, no. 2, pp. 369-374, 1998.

[35] M. Suganuma, S. Okabe, M. Oniyama, Y. Tada, H. Ito, and H. Fujiki, "Wide distribution of $[3 \mathrm{H}](-)$-epigallocatechin gallate, a cancer preventive tea polyphenol, in mouse tissue," Carcinogenesis, vol. 19, no. 10, pp. 1771-1776, 1998.

[36] M. M. Abd El Mohsen, G. Kuhnle, A. R. Rechner et al., "Uptake and metabolism of epicatechin and its access to the brain after oral ingestion," Free Radical Biology and Medicine, vol. 33, no. 12, pp. 1693-1702, 2002.

[37] M. A. El Mohsen, J. Marks, G. Kuhnle et al., "Absorption, tissue distribution and excretion of pelargonidin and its metabolites following oral administration to rats," British Journal of Nutrition, vol. 95, no. 1, pp. 51-58, 2006.

[38] S. Talavéra, C. Felgines, O. Texier et al., "Anthocyanin metabolism in rats and their distribution to digestive area, kidney, and brain," Journal of Agricultural and Food Chemistry, vol. 53, no. 10, pp. 3902-3908, 2005.

[39] M. Fridén, H. Ljungqvist, B. Middleton, U. Bredberg, and M. Hammarlund-Udenaes, "Improved measurement of drug exposure in the brain using drug-specific correction for residual blood," Journal of Cerebral Blood Flow and Metabolism, vol. 30, no. 1, pp. 150-161, 2010.

[40] S. Schaffer and B. Halliwell, "Do polyphenols enter the brain and does it matter? Some theoretical and practical considerations," Genes \& Nutrition, vol. 7, no. 2, pp. 99-109, 2012.

[41] S. Passamonti, U. Vrhovsek, A. Vanzo, and F. Mattivi, "Fast access of some grape pigments to the brain," Journal of Agricultural and Food Chemistry, vol. 53, no. 18, pp. 7029-7034, 2005.

[42] W. Kalt, J. B. Blumberg, J. E. McDonald et al., "Identification of anthocyanins in the liver, eye, and brain of blueberry-fed pigs," Journal of Agricultural and Food Chemistry, vol. 56, no. 3, pp. 705-712, 2008.

[43] P. E. Milbury and W. Kalt, "Xenobiotic metabolism and berry flavonoid transport across the blood? Brain barrier," Journal of Agricultural and Food Chemistry, vol. 58, no. 7, pp. 39503956, 2010.

[44] E. M. Janle, M. A. Lila, M. Grannan et al., "Pharmacokinetics and tissue distribution of 14C-Labeled grape polyphenols in the periphery and the central nervous system following oral administration," Journal of Medicinal Food, vol. 13, no. 4, pp. 926-933, 2010.

[45] D. Commenges, V. Scotet, S. Renaud, H. Jacqmin-Gadda, P. Barberger-Gateau, and J. F. Dartigues, "Intake of flavonoids and risk of dementia," European Journal of Epidemiology, vol. 16, no. 4, pp. 357-363, 2000.

[46] J. P. E. Spencer, "Food for thought: the role of dietary flavonoids in enhancing human memory, learning and neurocognitive performance," Proceedings of the Nutrition Society, vol. 67, no. 2, pp. 238-252, 2008.

[47] J. P. E. Spencer, "Flavonoids: modulators of brain function?" British Journal of Nutrition, vol. 99, no. 1, pp. ES60-ES77, 2008.

[48] E. Nurk, H. Refsum, C. A. Drevon et al., "Intake of flavonoidrich wine, tea, and chocolate by elderly men and women is associated with better cognitive test performance1-3," Journal of Nutrition, vol. 139, no. 1, pp. 120-127, 2009.

[49] K. Beking and A. Vieira, "Flavonoid intake and disabilityadjusted life years due to Alzheimers and related dementias: a population-based study involving twenty-three developed countries," Public Health Nutrition, vol. 13, no. 9, pp. 1403 1409, 2010.
[50] E. Kesse-Guyot, L. Fezeu, V. A. Andreeva et al., "Total and specific polyphenol intakes in midlife are associated with cognitive function measured 13 years later," Journal of Nutrition, vol. 142, no. 1, pp. 76-83, 2012.

[51] P. Barberger-Gateau, C. Raffaitin, L. Letenneur et al., "Dietary patterns and risk of dementia: the Three-City cohort study," Neurology, vol. 69, no. 20, pp. 1921-1930, 2007.

[52] J. A. Joseph, B. Shukitt-Hale, N. A. Denisova et al., "Reversals of age-related declines in neuronal signal transduction, cognitive, and motor behavioral deficits with blueberry, spinach, or strawberry dietary supplementation," Journal of Neuroscience, vol. 19, no. 18, pp. 8114-8121, 1999.

[53] W. D. Crews Jr., D. W. Harrison, M. L. Griffin et al., "A double-blinded, placebo-controlled, randomized trial of the neuropsychologic efficacy of cranberry juice in a sample of cognitively intact older adults: pilot study findings," Journal of Alternative and Complementary Medicine, vol. 11, no. 2, pp. 305-309, 2005.

[54] R. Krikorian, T. A. Nash, M. D. Shidler, B. Shukitt-Hale, and J. A. Joseph, "Concord grape juice supplementation improves memory function in older adults with mild cognitive impairment," British Journal of Nutrition, vol. 103, no. 5, pp. 730734, 2010.

[55] R. Krikorian, M. D. Shidler, T. A. Nash et al., "Blueberry supplementation improves memory in older adults," Journal of Agricultural and Food Chemistry, vol. 58, no. 7, pp. 39964000, 2010

[56] P. Goyarzu, D. H. Malin, F. C. Lau et al., "Blueberry supplemented diet: effects on object recognition memory and nuclear factor-kappa B levels in aged rats," Nutritional Neuroscience, vol. 7, no. 2, pp. 75-83, 2004.

[57] D. Barros, O. B. Amaral, I. Izquierdo et al., "Behavioral and genoprotective effects of Vaccinium berries intake in mice," Pharmacology Biochemistry and Behavior, vol. 84, no. 2, pp. 229-234, 2006.

[58] M. R. Ramirez, I. Izquierdo, M. D. C. Bassols Raseira, J. Â. Zuanazzi, D. Barros, and A. T. Henriques, "Effect of lyophilised Vaccinium berries on memory, anxiety and locomotion in adult rats," Pharmacological Research, vol. 52, no. 6, pp. 457-462, 2005.

[59] S. N. Burke and C. A. Barnes, "Neural plasticity in the ageing brain," Nature Reviews Neuroscience, vol. 7, no. 1, pp. 30-40, 2006.

[60] D. Stangl and S. Thuret, "Impact of diet on adult hippocampal neurogenesis," Genes and Nutrition, vol. 4, no. 4, pp. 271282, 2009.

[61] A. K. Patel, J. T. Rogers, X. Huang et al., "Flavanols, mild cognitive impairment, and Alzheimer's dementia," International Journal of Clinical and Experimental Medicine, vol. 1, no. 2, pp. 181-191, 2008.

[62] H. van Praag, M. J. Lucero, G. W. Yeo et al., "Plant-derived flavanol (-)epicatechin enhances angiogenesis and retention of spatial memory in mice," Journal of Neuroscience, vol. 27, no. 22, pp. 5869-5878, 2007.

[63] H. Schroeter, C. Heiss, J. Balzer et al., "(-)-Epicatechin mediates beneficial effects of flavanol-rich cocoa on vascular function in humans," Proceedings of the National Academy of Sciences of the United States of America, vol. 103, no. 4, pp. 1024-1029, 2006.

[64] C. Heiss, A. Dejam, P. Kleinbongard, T. Schewe, H. Sies, and M. Kelm, "Vascular effects of cocoa rich in flavan-3-ols," Journal of the American Medical Association, vol. 290, no. 8, pp. 1030-1031, 2003. 
[65] C. Heiss, D. Finis, P. Kleinbongard et al., "Sustained increase in flow-mediated dilation after daily intake of high-flavanol cocoa drink over 1 week," Journal of Cardiovascular Pharmacology, vol. 49, no. 2, pp. 74-80, 2007.

[66] F. A. Sorond, L. A. Lipsitz, N. K. Hollenberg, and N. D. L. Fisher, "Cerebral blood flow response to flavanol-rich cocoa in healthy elderly humans," Neuropsychiatric Disease and Treatment, vol. 4, no. 2, pp. 433-440, 2008.

[67] S. T. Francis, K. Head, P. G. Morris, and I. A. Macdonald, "The effect of flavanol-rich cocoa on the fMRI response to a cognitive task in healthy young people," Journal of Cardiovascular Pharmacology, vol. 47, no. 2, pp. S215-S220, 2006.

[68] F. H. Gage, "Mammalian neural stem cells," Science, vol. 287, no. 5457, pp. 1433-1438, 2000.

[69] C. Zhao, W. Deng, and F. H. Gage, "Mechanisms and functional implications of adult neurogenesis," Cell, vol. 132, no. 4, pp. 645-660, 2008.

[70] T. D. Palmer, A. R. Willhoite, and F. H. Gage, "Vascular niche for adult hippocampal neurogenesis," The Journal of Comparative Neurology, vol. 425, no. 4, pp. 479-494, 2000.

[71] C. Cohen-Salmon, P. Venault, B. Martin et al., "Effects of Ginkgo biloba extract (EGb 761) on learning and possible actions on aging," Journal of Physiology Paris, vol. 91, no. 6, pp. 291-300, 1997.

[72] B. J. Diamond, S. C. Shiflett, N. Feiwel et al., "Ginkgo biloba extract: mechanisms and clinical indications," Archives of Physical Medicine and Rehabilitation, vol. 81, no. 5, pp. 668678, 2000.

[73] T. M. Itil, E. Eralp, I. Ahmed, A. Kunitz, and K. Z. Itil, "The pharmacological effects of Ginkgo biloba, a plant extract, on the brain of dementia patients in comparison with tacrine," Psychopharmacology Bulletin, vol. 34, no. 3, pp. 391-397, 1998.

[74] J. R. Hoffman, A. Donato, and S. J. Robbins, "Ginkgo biloba promotes short-term retention of spatial memory in rats," Pharmacology Biochemistry and Behavior, vol. 77, no. 3, pp. 533-539, 2004.

[75] Y. Wang, L. Wang, J. Wu, and J. Cai, "The in vivo synaptic plasticity mechanism of EGb 761-induced enhancement of spatial learning and memory in aged rats," British Journal of Pharmacology, vol. 148, no. 2, pp. 147-153, 2006.

[76] Y. Oyama, L. Chikahisa, T. Ueha, K. Kanemaru, and K. Noda, "Ginkgo biloba extract protects brain neurons against oxidative stress induced by hydrogen peroxide," Brain Research, vol. 712, no. 2, pp. 349-352, 1996.

[77] A. Gajewski and S. A. Hensch, "Ginkgo biloba and memory for a maze," Psychological Reports, vol. 84, no. 2, pp. 481-484, 1999.

[78] S. Stoll, K. Scheuer, O. Pohl, and W. E. Müller, "Ginkgo biloba extract (EGb 761) independently improves changes in passive avoidance learning and brain membrane fluidity in the aging mouse," Pharmacopsychiatry, vol. 29, no. 4, pp. 144-149, 1996.

[79] P. Chopin and M. Briley, "Effects of four non-cholinergic cognitive enhancers in comparison with tacrine and galanthamine on scopolamine-induced amnesia in rats," Psychopharmacology, vol. 106, no. 1, pp. 26-30, 1992.

[80] C. Ramassamy, F. Clostre, Y. Christen, and J. Costentin, "Prevention by a Ginkgo biloba extract (GBE 761) of the dopaminergic neurotoxicity of MPTP," Journal of Pharmacy and Pharmacology, vol. 42, no. 11, pp. 785-789, 1990.

[81] C. M. H. Watanabe, S. Wolffram, P. Ader et al., "The in vivo neuromodulatory effects of the herbal medicine Ginkgo biloba," Proceedings of the National Academy of Sciences of the United States of America, vol. 98, no. 12, pp. 6577-6580, 2001.

[82] H. Checkoway, K. Powers, T. Smith-Weller, G. M. Franklin, W. T. Longstreth Jr., and P. D. Swanson, "Parkinson's disease risks associated with cigarette smoking, alcohol consumption, and caffeine intake," American Journal of Epidemiology, vol. 155, no. 8, pp. 732-738, 2002.

[83] D. M. Walsh and D. J. Selkoe, "A $\beta$ oligomers-a decade of discovery," Journal of Neurochemistry, vol. 101, no. 5, pp. 1172-1184, 2007.

[84] J. J. Yan, J. Y. Cho, H. S. Kim et al., "Protection against $\beta$ amyloid peptide toxicity in vivo with long-term administration of ferulic acid," British Journal of Pharmacology, vol. 133, no. 1, pp. 89-96, 2001.

[85] K. Rezai-Zadeh, G. W. Arendash, H. Hou et al., "Green tea epigallocatechin-3-gallate (EGCG) reduces $\beta$-amyloid mediated cognitive impairment and modulates tau pathology in Alzheimer transgenic mice," Brain Research, vol. 1214, no. C, pp. 177-187, 2008.

[86] Q. Li, H. F. Zhao, Z. F. Zhang et al., "Long-term green tea catechin administration prevents spatial learning and memory impairment in senescence-accelerated mouse prone- 8 mice by decreasing $A \beta 1-42$ oligomers and upregulating synaptic plasticity-related proteins in the hippocampus," Neuroscience, vol. 163, no. 3, pp. 741-749, 2009.

[87] K. Ono, Y. Yoshiike, A. Takashima, K. Hasegawa, H. Naiki, and M. Yamada, "Potent anti-amyloidogenic and fibril-destabilizing effects of polyphenols in vitro: implications for the prevention and therapeutics of Alzheimer's disease," Journal of Neurochemistry, vol. 87, no. 1, pp. 172-181, 2003.

[88] K. Ono, M. M. Condron, L. Ho et al., "Effects of grape seedderived polyphenols on amyloid $\beta$-protein self-assembly and cytotoxicity," Journal of Biological Chemistry, vol. 283, no. 47, pp. 32176-32187, 2008.

[89] M. Hirohata, K. Hasegawa, S. Tsutsumi-Yasuhara et al., "The anti-amyloidogenic effect is exerted against Alzheimer's $\beta$ amyloid fibrils in vitro by preferential and reversible binding of flavonoids to the amyloid fibril structure," Biochemistry, vol. 46, no. 7, pp. 1888-1899, 2007.

[90] H. Onozuka, A. Nakajima, K. Matsuzaki et al., "Nobiletin, a citrus flavonoid, improves memory impairment and $\mathrm{A} \beta$ pathology in a transgenic mouse model of Alzheimer's disease," Journal of Pharmacology and Experimental Therapeutics, vol. 326, no. 3, pp. 739-744, 2008.

[91] J. W. Fernandez, K. Rezai-Zadeh, D. Obregon, and J. Tan, "EGCG functions through estrogen receptor-mediated activation of ADAM10 in the promotion of non-amyloidogenic processing of APP," FEBS Letters, vol. 584, no. 19, pp. 42594267, 2010

[92] K. Rezai-Zadeh, D. Shytle, N. Sun et al., "Green tea epigallocatechin-3-gallate (EGCG) modulates amyloid precursor protein cleavage and reduces cerebral amyloidosis in Alzheimer transgenic mice," Journal of Neuroscience, vol. 25, no. 38, pp. 8807-8814, 2005.

[93] S. A. Mandel, T. Amit, L. Kalfon, L. Reznichenko, O. Weinreb, and M. B. H. Youdim, "Cell signaling pathways and iron chelation in the neurorestorative activity of green tea polyphenols: special reference to epigallocatechin gallate (EGCG)," Journal of Alzheimer's Disease, vol. 15, no. 2, pp. 211-222, 2008.

[94] T. Amit, Y. Avramovich-Tirosh, M. B. H. Youdim, and S. Mandel, "Targeting multiple Alzheimer's disease etiologies with multimodal neuroprotective and neurorestorative iron 
chelators," The FASEB Journal, vol. 22, no. 5, pp. 1296-1305, 2008.

[95] S. Mandel, T. Amit, O. Bar-Am, and M. B. H. Youdim, "Iron dysregulation in Alzheimer's disease: multimodal brain permeable iron chelating drugs, possessing neuroprotectiveneurorescue and amyloid precursor protein-processing regulatory activities as therapeutic agents," Progress in Neurobiology, vol. 82, no. 6, pp. 348-360, 2007.

[96] D. E. Ehrnhoefer, J. Bieschke, A. Boeddrich et al., "EGCG redirects amyloidogenic polypeptides into unstructured, offpathway oligomers," Nature Structural and Molecular Biology, vol. 15, no. 6, pp. 558-566, 2008.

[97] T. Mori, K. Rezai-Zadeh, N. Koyama et al., "Tannic acid is a natural beta-secretase inhibitor that prevents cognitive impairment and mitigates Alzheimer-like pathology in transgenic mice," The Journal of Biological Chemistry, vol. 287, no. 9, pp. 6912-6927, 2012.

[98] R. J. Williams and J. P. Spencer, "Flavonoids, cognition, and dementia: actions, mechanisms, and potential therapeutic utility for Alzheimer disease," Free Radical Biology \& Medicine, vol. 52, no. 1, pp. 35-45, 2012.

[99] S. Mandel and M. B. H. Youdim, "Catechin polyphenols: neurodegeneration and neuroprotection in neurodegenerative diseases," Free Radical Biology and Medicine, vol. 37, no. 3, pp. 304-317, 2004.

[100] O. Weinreb, S. Mandel, T. Amit, and M. B. H. Youdim, "Neurological mechanisms of green tea polyphenols in Alzheimer's and Parkinson's diseases," Journal of Nutritional Biochemistry, vol. 15, no. 9, pp. 506-516, 2004.

[101] S. A. Mandel, T. Amit, O. Weinreb, and M. B. H. Youdim, "Understanding the broad-spectrum neuroprotective action profile of green tea polyphenols in aging and neurodegenerative diseases," Journal of Alzheimer's Disease, vol. 25, no. 2, pp. 187-208, 2011.

[102] Y. Levites, M. B. H. Youdim, G. Maor, and S. Mandel, “Attenuation of 6-hydroxydopamine (6-OHDA)-induced nuclear factor-kappaB (NF- $\kappa \mathrm{B})$ activation and cell death by tea extracts in neuronal cultures," Biochemical Pharmacology, vol. 63, no. 1, pp. 21-29, 2002.

[103] Y. Levites, O. Weinreb, G. Maor, M. B. H. Youdim, and S. Mandel, "Green tea polyphenol (-)-epigallocatechin-3gallate prevents N-methyl-4-phenyl- 1,2,3,6-tetrahydropyridine-induced dopaminergic neurodegeneration," Journal of Neurochemistry, vol. 78, no. 5, pp. 1073-1082, 2001.

[104] J. P. E. Spencer, M. Whiteman, P. Jenner, and B. Halliwell, "5$\mathrm{S}$-cysteinyl-conjugates of catecholamines induce cell damage, extensive DNA base modification and increases in caspase-3 activity in neurons," Journal of Neurochemistry, vol. 81, no. 1, pp. 122-129, 2002.

[105] D. Vauzour, G. Ravaioli, K. Vafeiadou, A. Rodriguez-Mateos, C. Angeloni, and J. P. E. Spencer, "Peroxynitrite induced formation of the neurotoxins 5-S-cysteinyl-dopamine and DHBT-1: implications for Parkinson's disease and protection by polyphenols," Archives of Biochemistry and Biophysics, vol. 476, no. 2, pp. 145-151, 2008.

[106] D. Vauzour, G. Corona, and J. P. E. Spencer, "Caffeic acid, tyrosol and p-coumaric acid are potent inhibitors of 5-S-cysteinyl-dopamine induced neurotoxicity," Archives of Biochemistry and Biophysics, vol. 501, no. 1, pp. 106-111, 2010.

[107] D. Vauzour, K. Vafeiadou, and J. P. E. Spencer, "Inhibition of the formation of the neurotoxin 5-S-cysteinyl-dopamine by polyphenols," Biochemical and Biophysical Research Communications, vol. 362, no. 2, pp. 340-346, 2007.
[108] H. Li and G. Dryhurst, "Oxidative metabolites of 5-S-cysteinyldopamine inhibit the pyruvate dehydrogenase complex," Journal of Neural Transmission, vol. 108, no. 12, pp. 13631374, 2001.

[109] E. C. Hirsch, S. Hunot, and A. Hartmann, "Neuroinflammatory processes in Parkinson's disease," Parkinsonism and Related Disorders, vol. 11, supplement 1, pp. S9-S15, 2005.

[110] P. Agostinho, R. A. Cunha, and C. Oliveira, "Neuroinflammation, oxidative stress and the pathogenesis of Alzheimer's disease," Current Pharmaceutical Design, vol. 16, no. 25, pp. 2766-2778, 2010.

[111] D. Praticò and J. Q. Trojanowski, "Inflammatory hypotheses: novel mechanisms of Alzheimer's neurodegeneration and new therapeutic targets?" Neurobiology of Aging, vol. 21, no. 3, pp. 441-445, 2000.

[112] A. G. Ceulemans, T. Zgavc, R. Kooijman, S. Hachimi-Idrissi, S. Sarre, and Y. Michotte, "The dual role of the neuroinflammatory response after ischemic stroke: modulatory effects of hypothermia," Journal of Neuroinflammation, vol. 7, article $74,2010$.

[113] V. C. Stewart and S. J. R. Heales, "Nitric oxide-induced mitochondrial dysfunction: implications for neurodegeneration," Free Radical Biology and Medicine, vol. 34, no. 3, pp. 287-303, 2003.

[114] S. Moncada and J. P. Bolaños, "Nitric oxide, cell bioenergetics and neurodegeneration," Journal of Neurochemistry, vol. 97, no. 6, pp. 1676-1689, 2006.

[115] L. Qin, Y. Liu, T. Wang et al., "NADPH oxidase mediates lipopolysaccharide-induced neurotoxicity and proinflammatory gene expression in activated microglia," Journal of Biological Chemistry, vol. 279, no. 2, pp. 1415-1421, 2004.

[116] A. Bal-Price, A. Matthias, and G. C. Brown, "Stimulation of the NADPH oxidase in activated rat microglia removes nitric oxide but induces peroxynitrite production," Journal of Neurochemistry, vol. 80, no. 1, pp. 73-80, 2002.

[117] A. Y. Abramov, J. Jacobson, F. Wientjes, J. Hothersall, L. Canevari, and M. R. Duchen, "Expression and modulation of an NADPH oxidase in mammalian astrocytes," Journal of Neuroscience, vol. 25, no. 40, pp. 9176-9184, 2005.

[118] G. C. Brown and A. Bal-Price, "Inflammatory neurodegeneration mediated by nitric oxide, glutamate, and mitochondria," Molecular Neurobiology, vol. 27, no. 3, pp. 325-355, 2003.

[119] D. J. MacEwan, "TNF receptor subtype signalling: differences and cellular consequences," Cellular Signalling, vol. 14, no. 6, pp. 477-492, 2002.

[120] D. L. Taylor, F. Jones, E. S. F. Chen Seho Kubota, and J. M. Pocock, "Stimulation of microglial metabotropic glutamate receptor mGlu2 triggers tumor necrosis factor $\alpha$-induced neurotoxicity in concert with microglial-derived Fas ligand," Journal of Neuroscience, vol. 25, no. 11, pp. 2952-2964, 2005.

[121] C. A. Szekely, J. E. Thorne, P. P. Zandi et al., "Nonsteroidal anti-inflammatory drugs for the prevention of Alzheimer's disease: a systematic review," Neuroepidemiology, vol. 23, no. 4, pp. 159-169, 2004.

[122] J. González-Gallego, M. V. García, S. Sánchez-Campos, and M. J. Tuñó, "Fruit polyphenols, immunity and inflammation," British Journal of Nutrition, vol. 104, supplement 3, pp. S15-S27, 2010.

[123] J. P. Spencer, K. Vafeiadou, R. J. Williams, and D. Vauzour, "Neuroinflammation: modulation by flavonoids and mechanisms of action," Molecular Aspects of Medicine, vol. 33, no. 1, pp. 83-97, 2012. 
[124] T. K. Kao, Y. C. Ou, S. L. Raung, C. Y. Lai, S. L. Liao, and C. J. Chen, "Inhibition of nitric oxide production by quercetin in endotoxin/cytokine-stimulated microglia," Life Sciences, vol. 86, no. 9-10, pp. 315-321, 2010.

[125] V. Sharma, M. Mishra, S. Ghosh et al., "Modulation of interleukin- $1 \beta$ mediated inflammatory response in human astrocytes by flavonoids: implications in neuroprotection," Brain Research Bulletin, vol. 73, no. 1-3, pp. 55-63, 2007.

[126] G. Bureau, F. Longpré, and M. G. Martinoli, "Resveratrol and quercetin, two natural polyphenols, reduce apoptotic neuronal cell death induced by neuroinflammation," Journal of Neuroscience Research, vol. 86, no. 2, pp. 403-410, 2008.

[127] K. Vafeiadou, D. Vauzour, H. Y. Lee, A. Rodriguez-Mateos, R. J. Williams, and J. P. E. Spencer, "The citrus flavanone naringenin inhibits inflammatory signalling in glial cells and protects against neuroinflammatory injury," Archives of Biochemistry and Biophysics, vol. 484, no. 1, pp. 100-109, 2009.

[128] F. C. Lau, D. F. Bielinski, and J. A. Joseph, "Inhibitory effects of blueberry extract on the production of inflammatory mediators in lipopolysaccharide-activated BV2 microglia," Journal of Neuroscience Research, vol. 85, no. 5, pp. 1010-1017, 2007.

[129] Y. Steffen, C. Gruber, T. Schewe, and H. Sies, "Mono-Omethylated flavanols and other flavonoids as inhibitors of endothelial NADPH oxidase," Archives of Biochemistry and Biophysics, vol. 469, no. 2, pp. 209-219, 2008.

[130] G. Martino, L. Adorini, P. Rieckmann et al., "Inflammation in multiple sclerosis: the good, the bad, and the complex," Lancet Neurology, vol. 1, no. 8, pp. 499-509, 2002.

[131] O. Aktas, T. Prozorovski, A. Smorodchenko et al., "Green tea epigallocatechin-3-gallate mediates $\mathrm{T}$ cellular NF- $\kappa \mathrm{B}$ inhibition and exerts neuroprotection in autoimmune encephalomyelitis," Journal of Immunology, vol. 173, no. 9, pp. 57945800, 2004.

[132] G. Muthian and J. J. Bright, "Quercetin, a flavonoid phytoestrogen, ameliorates experimental allergic encephalomyelitis by blocking IL-12 signaling through JAK-STAT pathway in T lymphocyte," Journal of Clinical Immunology, vol. 24, no. 5, pp. 542-552, 2004.

[133] T. J. Imler Jr. and T. M. Petro, "Decreased severity of experimental autoimmune encephalomyelitis during resveratrol administration is associated with increased $\mathrm{IL}-17^{+} \mathrm{IL}-10^{+} \mathrm{T}$ cells, CD4- IFN- $\gamma^{+}$cells, and decreased macrophage IL-6 expression," International Immunopharmacology, vol. 9, no. 1, pp. 134-143, 2009.

[134] B. Halliwell, "Oxidative stress and neurodegeneration: where are we now?" Journal of Neurochemistry, vol. 97, no. 6, pp. 1634-1658, 2006.

[135] A. S. Pannala, C. A. Rice-Evans, B. Halliwell, and S. Singh, "Inhibition of peroxynitrite-mediated tyrosine nitration by catechin polyphenols," Biochemical and Biophysical Research Communications, vol. 232, no. 1, pp. 164-168, 1997.

[136] A. Russo, R. Acquaviva, A. Campisi et al., "Bioflavonoids as antiradicals, antioxidants and DNA cleavage protectors," Cell Biology and Toxicology, vol. 16, no. 2, pp. 91-98, 2000.

[137] F. Visioli, G. Bellomo, and C. Galli, "Free radical-scavenging properties of olive oil polyphenols," Biochemical and Biophysical Research Communications, vol. 247, no. 1, pp. 60-64, 1998.

[138] H. Schroeter, P. Bahia, J. P. E. Spencer et al., "(-)Epicatechin stimulates ERK-dependent cyclic AMP response element activity and up-regulates GluR2 in cortical neurons," Journal of Neurochemistry, vol. 101, no. 6, pp. 1596-1606, 2007.
[139] H. Schroeter, J. P. E. Spencer, C. Rice-Evans, and R. J. Williams, "Flavonoids protect neurons from oxidized lowdensity-lipoprotein-induced apoptosis involving c-Jun Nterminal kinase (JNK), c-Jun and caspase-3," Biochemical Journal, vol. 358, no. 3, pp. 547-557, 2001.

[140] D. Vauzour, K. Vafeiadou, C. Rice-Evans, R. J. Williams, and J. P. E. Spencer, "Activation of pro-survival Akt and ERK1/2 signalling pathways underlie the anti-apoptotic effects of flavanones in cortical neurons," Journal of Neurochemistry, vol. 103, no. 4, pp. 1355-1367, 2007.

[141] M. P. Mattson and A. Cheng, "Neurohormetic phytochemicals: low-dose toxins that induce adaptive neuronal stress responses," Trends in Neurosciences, vol. 29, no. 11, pp. 632639, 2006.

[142] E. J. Calabrese, "Neuroscience and hormesis: overview and general findings," Critical Reviews in Toxicology, vol. 38, no. 4, pp. 249-252, 2008.

[143] A. D. Kraft, D. A. Johnson, and J. A. Johnson, "Nuclear factor E2-related factor 2-dependent antioxidant response element activation by tert-butylhydroquinone and sulforaphane occurring preferentially in astrocytes conditions neurons against oxidative insult," Journal of Neuroscience, vol. 24, no. 5, pp. 1101-1112, 2004.

[144] J. M. Lee and J. A. Johnson, "An important role of Nrf2ARE pathway in the cellular defense mechanism," Journal of Biochemistry and Molecular Biology, vol. 37, no. 2, pp. 139143, 2004.

[145] K. Itoh, N. Wakabayashi, Y. Katoh et al., "Keap1 represses nuclear activation of antioxidant responsive elements by Nrf2 through binding to the amino-terminal Neh2 domain," Genes and Development, vol. 13, no. 1, pp. 76-86, 1999.

[146] T. Nguyen, P. J. Sherratt, and C. B. Pickett, "Regulatory mechanisms controlling gene expression mediated by the antioxidant response element," Annual Review of Pharmacology and Toxicology, vol. 43, pp. 233-260, 2003.

[147] C. Y. Chen, J. H. Jang, M. H. Li, and Y. J. Surh, "Resveratrol upregulates heme oxygenase-1 expression via activation of NF-E2-related factor 2 in PC12 cells," Biochemical and Biophysical Research Communications, vol. 331, no. 4, pp. 9931000, 2005.

[148] J. Ren, C. Fan, N. Chen, J. Huang, and Q. Yang, "Resveratrol pretreatment attenuates cerebral ischemic injury by upregulating expression of transcription factor $\mathrm{Nrf} 2$ and $\mathrm{HO}-1$ in rats," Neurochemical Research, vol. 36, no. 12, pp. 2352-2362, 2011.

[149] Y. Kurauchi, A. Hisatsune, Y. Isohama, S. Mishima, and H. Katsuki, "Caffeic acid phenethylester protects nigral dopaminergic neurons via dual mechanisms involving heme oxygenase-1 and brain-derived neurotrophic factor," British Journal of Pharmacology. In press.

[150] G. Scapagnini, D. A. Butterfield, C. Colombrita, R. Sultana, A. Pascale, and V. Calabrese, "Ethyl ferulate, a lipophilic polyphenol, induces HO-1 and protects rat neurons against oxidative stress," Antioxidants and Redox Signaling, vol. 6, no. 5, pp. 811-818, 2004.

[151] Z. A. Shah, R. C. Li, A. S. Ahmad et al., "The flavanol (-)epicatechin prevents stroke damage through the Nrf2/HO1 pathway," Journal of Cerebral Blood Flow and Metabolism, vol. 30, no. 12, pp. 1951-1961, 2010.

[152] P. K. Bahia, M. Rattray, and R. J. Williams, "Dietary flavonoid (-)epicatechin stimulates phosphatidylinositol 3kinase-dependent anti-oxidant response element activity and up-regulates glutathione in cortical astrocytes," Journal of Neurochemistry, vol. 106, no. 5, pp. 2194-2204, 2008. 
[153] C. Boesch-Saadatmandi, J. Niering, A. M. Minihane et al., "Impact of apolipoprotein E genotype and dietary quercetin on paraoxonase 1 status in apoE3 and apoE4 transgenic mice," Atherosclerosis, vol. 211, no. 1, pp. 110-113, 2010.

[154] C. Boesch-Saadatmandi, S. Wolffram, A. M. Minihane, and G. Rimbach, "Effect of apoE genotype and dietary quercetin on blood lipids and TNF- $\alpha$ levels in apoE3 and apoE4 targeted gene replacement mice," British Journal of Nutrition, vol. 101, no. 10, pp. 1440-1443, 2009.

[155] S. Egert, C. Boesch-Saadatmandi, S. Wolffram, G. Rimbach, and M. J. Müller, "Serum lipid and blood pressure responses to quercetin vary in overweight patients by apolipoprotein $\mathrm{E}$ genotype," Journal of Nutrition, vol. 140, no. 2, pp. 278-284, 2010.

[156] A. C. Graeser, C. Boesch-Saadatmandi, J. Lippmann et al., "Nrf2-dependent gene expression is affected by the proatherogenic apoE4 genotype-studies in targeted gene replacement mice," Journal of Molecular Medicine, vol. 89, no. 10, pp. 1027-1035, 2011.

[157] S. Impey, D. M. Smith, K. Obrietan, R. Donahue, C. Wade, and D. R. Storm, "Stimulation of cAMP response element (CRE)-mediated transcription during contextual learning," Nature Neuroscience, vol. 1, no. 7, pp. 595-601, 1998.

[158] R. Bourtchuladze, B. Frenguelli, J. Blendy, D. Cioffi, G. Schutz, and A. J. Silva, "Deficient long-term memory in mice with a targeted mutation of the cAMP- responsive elementbinding protein," Cell, vol. 79, no. 1, pp. 59-68, 1994.

[159] S. Finkbeiner, "CREB couples neurotrophin signals to survival messages," Neuron, vol. 25, no. 1, pp. 11-14, 2000.

[160] T. Tully, R. Bourtchouladze, R. Scott, and J. Tallman, “Targeting the creb pathway for memory enhancers," Nature Reviews Drug Discovery, vol. 2, no. 4, pp. 267-277, 2003.

[161] S. Finkbeiner, S. F. Tavazoie, A. Maloratsky, K. M. Jacobs, K. M. Harris, and M. E. Greenberg, "CREB: a major mediator of neuronal neurotrophin responses," Neuron, vol. 19, no. 5, pp. 1031-1047, 1997.

[162] A. N. T. Kong, R. Yu, C. Chen, S. Mandlekar, and T. Primiano, "Signal transduction events elicited by natural products: role of MAPK and caspase pathways in homeostatic response and induction of apoptosis," Archives of Pharmacal Research, vol. 23, no. 1, pp. 1-16, 2000.

[163] C. J. Vlahos, W. F. Matter, K. Y. Hui, and R. F. Brown, "A specific inhibitor of phosphatidylinositol 3-kinase, 2-(4-morpholinyl)-8-phenyl-4H-1-benzopyran-4-one (LY294002)," Journal of Biological Chemistry, vol. 269, no. 7, pp. 52415248, 1994.

[164] G. M. Schratt, E. A. Nigh, W. G. Chen, L. Hu, and M. E. Greenberg, "BDNF regulates the translation of a select group of mRNAs by a mammalian target of rapamycin-phosphatidylinositol 3-kinase-dependent pathway during neuronal development," Journal of Neuroscience, vol. 24, no. 33, pp. 7366-7377, 2004.

[165] Y. Yin, G. M. Edelman, and P. W. Vanderklish, "The brainderived neurotrophic factor enhances synthesis of Arc in synaptoneurosomes," Proceedings of the National Academy of Sciences of the United States of America, vol. 99, no. 4, pp. 2368-2373, 2002.

[166] R. Waltereit, B. Dammermann, P. Wulff et al., "Arg3.1/Arc mRNA induction by $\mathrm{Ca}^{+}$and cAMP requires protein kinase a and mitogen-activated protein kinase/extracellular regulated kinase activation," Journal of Neuroscience, vol. 21, no. 15, pp. 5484-5493, 2001.
[167] Y. Levites, T. Amit, M. B. H. Youdim, and S. Mandel, "Involvement of protein kinase $\mathrm{C}$ activation and cell sur$\mathrm{vival} /$ cell cycle genes in green tea polyphenol (-)-epigallocatechin 3-gallate neuroprotective action," Journal of Biological Chemistry, vol. 277, no. 34, pp. 30574-30580, 2002.

[168] H. Ito, X. L. Sun, M. Watanabe, M. Okamoto, and T. Hatano, "Chlorogenic acid and its metabolite m-coumaric acid evoke neurite outgrowth in hippocampal neuronal cells," Bioscience, Biotechnology and Biochemistry, vol. 72, no. 3, pp. 885-888, 2008.

[169] L. Reznichenko, T. Amit, M. B. H. Youdim, and S. Mandel, "Green tea polyphenol (-)-epigallocatechin-3-gallate induces neurorescue of long-term serum-deprived PC12 cells and promotes neurite outgrowth," Journal of Neurochemistry, vol. 93, no. 5, pp. 1157-1167, 2005.

[170] S. Camandola and M. P. Mattson, "NF- $\kappa$ B as a therapeutic target in neurodegenerative diseases," Expert Opinion on Therapeutic Targets, vol. 11, no. 2, pp. 123-132, 2007.

[171] F. Zhang, L. Qian, P. M. Flood, J. S. Shi, J. S. Hong, and H. M. Gao, "Inhibition of I $\kappa$ B kinase- $\beta$ protects dopamine neurons against lipopolysaccharide-induced neurotoxicity," Journal of Pharmacology and Experimental Therapeutics, vol. 333, no. 3, pp. 822-833, 2010.

[172] Y. C. Liang, Y. T. Huang, S. H. Tsai, S. Y. Lin-Shiau, C. F. Chen, and J. K. Lin, "Suppression of inducible cyclooxygenase and inducible nitric oxide synthase by apigenin and related flavonoids in mouse macrophages," Carcinogenesis, vol. 20, no. 10, pp. 1945-1952, 1999.

[173] Q. Huang, L. J. Wu, S. I. Tashiro, H. Y. Gao, S. Onodera, and T. Ikejima, "(+)-catechin, an ingredient of green tea, protects murine microglia from oxidative stress-induced DNA damage and cell cycle arrest," Journal of Pharmacological Sciences, vol. 98, no. 1, pp. 16-24, 2005.

[174] H. Kim, Y. S. Kim, S. Y. Kim, and K. Suk, “The plant flavonoid wogonin suppresses death of activated C6 rat glial cells by inhibiting nitric oxide production," Neuroscience Letters, vol. 309, no. 1, pp. 67-71, 2001.

[175] P. Dell'Albani, R. Santangelo, L. Torrisi, V. G. Nicoletti, J. De Vellis, and A. M. Giuffrida Stella, "JAK/STAT signaling pathway mediates cytokine-induced iNOS expression in primary astroglial cell cultures," Journal of Neuroscience Research, vol. 65, no. 5, pp. 417-424, 2001.

[176] K. Suk, H. Lee, S. S. Kang, G. J. Cho, and W. S. Choi, "Flavonoid baicalein attenuates activation-induced cell death of brain microglia," Journal of Pharmacology and Experimental Therapeutics, vol. 305, no. 2, pp. 638-645, 2003.

[177] A. Spilsbury, D. Vauzour, J. P. Spencer, and M. Rattray, "Regulation of NF- $\kappa$ B activity in astrocytes: effects of flavonoids at dietary-relevant concentrations," Biochemical and Biophysical Research Communications, vol. 418, no. 3, pp. 578-583, 2012.

[178] S. Michan and D. Sinclair, "Sirtuins in mammals: insights into their biological function," Biochemical Journal, vol. 404, no. 1, pp. 1-13, 2007.

[179] J. A. Baur, K. J. Pearson, N. L. Price et al., "Resveratrol improves health and survival of mice on a high-calorie diet," Nature, vol. 444, no. 7117, pp. 337-342, 2006.

[180] M. D. Knutson and C. Leeuwenburgh, "Resveratrol and novel potent activators of SIRT1: effects on aging and age-related diseases," Nutrition Reviews, vol. 66, no. 10, pp. 591-596, 2008.

[181] J. A. Baur, "Resveratrol, sirtuins, and the promise of a DR mimetic," Mechanisms of Ageing and Development, vol. 131, no. 4, pp. 261-269, 2010. 
[182] S. J. Park, F. Ahmad, A. Philp et al., "Resveratrol ameliorates aging-related metabolic phenotypes by inhibiting cAMP phosphodiesterases," Cell, vol. 148, no. 3, pp. 421-433, 2012.

[183] B. L. Tang and C. E. L. Chua, "SIRT1 and neuronal diseases," Molecular Aspects of Medicine, vol. 29, no. 3, pp. 187-200, 2008.

[184] J. A. Parker, M. Arango, S. Abderrahmane et al., "Resveratrol rescues mutant polyglutamine cytotoxicity in nematode and mammalian neurons," Nature Genetics, vol. 37, no. 4, pp. 349-350, 2005.

[185] F. Yeung, J. E. Hoberg, C. S. Ramsey et al., "Modulation of NF- $\kappa \mathrm{B}$-dependent transcription and cell survival by the SIRT1 deacetylase," The EMBO Journal, vol. 23, no. 12, pp. 2369-2380, 2004.

[186] A. Crozier, D. Del Rio, M. N. Clifford et al., "Bioavailability of dietary flavonoids and phenolic compounds," Molecular Aspects of Medicine, vol. 31, no. 6, pp. 446-467, 2010.

[187] G. Williamson and M. N. Clifford, "Colonic metabolites of berry polyphenols: the missing link to biological activity?" British Journal of Nutrition, vol. 104, supplement 3, pp. S48S66, 2010. 


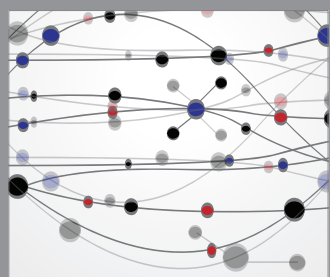

The Scientific World Journal
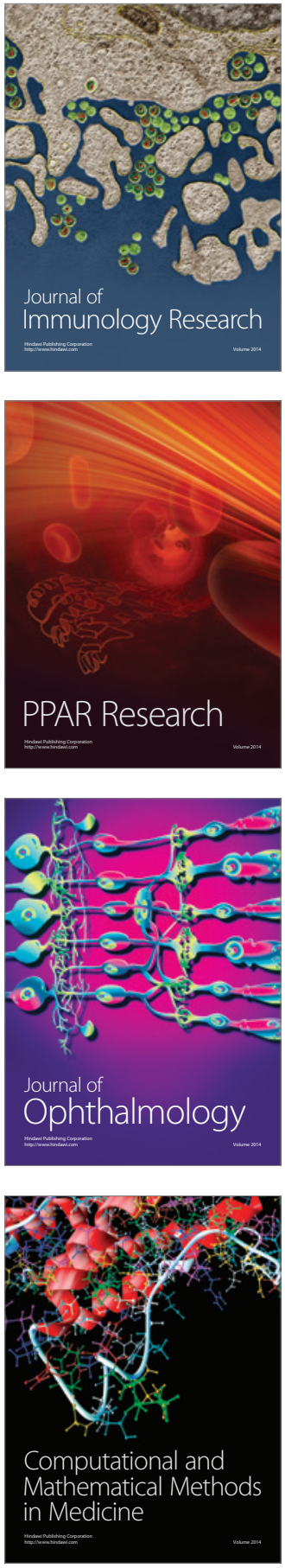

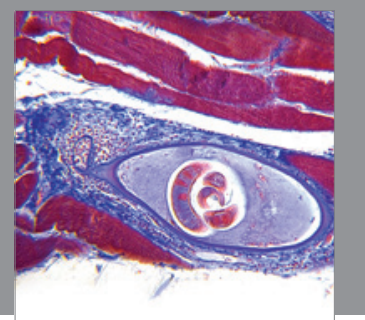

Gastroenterology

Research and Practice
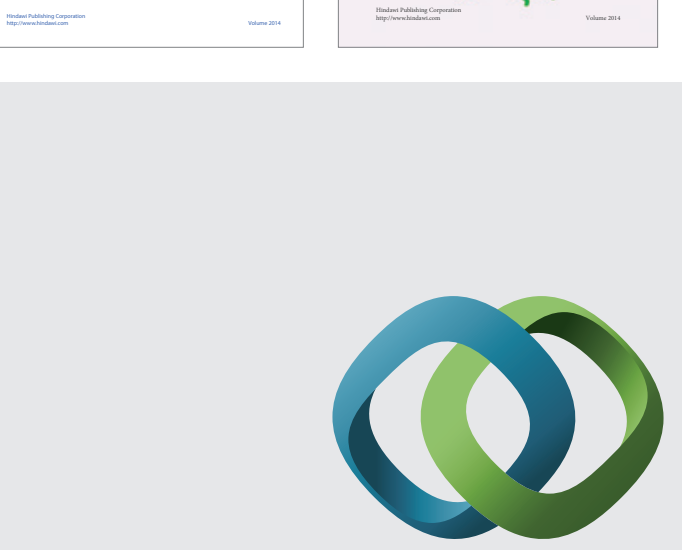

\section{Hindawi}

Submit your manuscripts at

http://www.hindawi.com
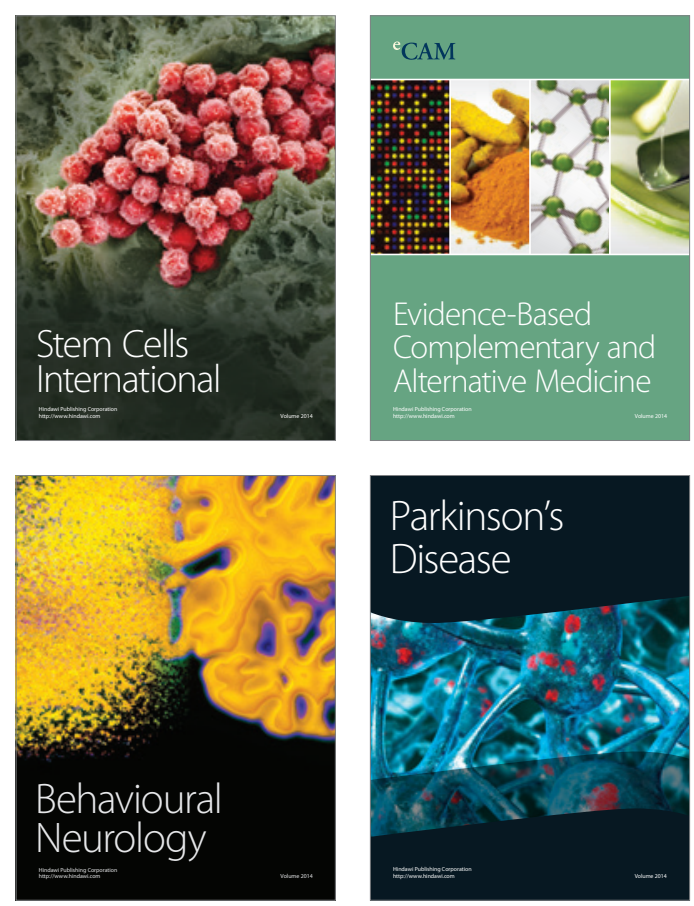

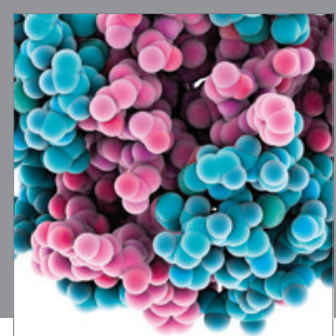

Journal of
Diabetes Research

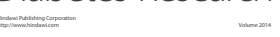

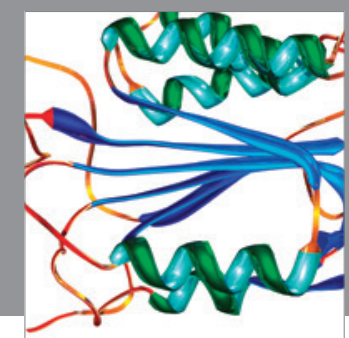

Disease Markers
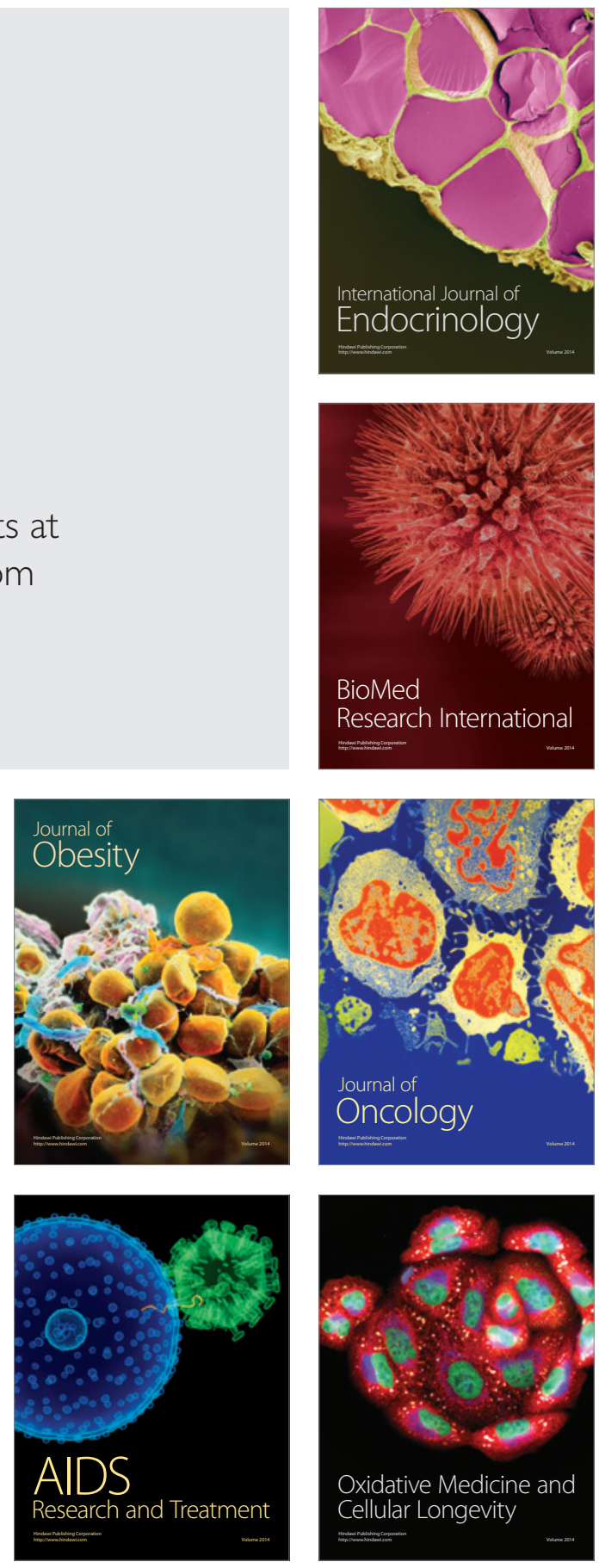